\title{
Dissorophid diversity at the early Permian cave system near Richards Spur, Oklahoma, USA
}

\author{
Bryan M. Gee, Joseph J. Bevitt, and Robert R. Reisz
}

\begin{abstract}
The early Permian karst deposits near Richards Spur, Oklahoma, preserve a diverse assemblage of terrestrial dissorophoid temnospondyls in an upland environment. The dissorophids, an armored dissorophoid clade, were previously represented only by two species of the eucacopine Cacops, Cacops morrisi and Cacops woehri, a genus also known from the lowland floodplains of the Texas red beds by the genotype $C$. aspidephorus. Here we report the first documented occurrences of two other dissorophid taxa at Richards Spur, Aspidosaurus and Dissorophus, identified on the basis of their distinctive osteoderms. Similar to Cacops, both taxa are also known from the Texas red beds and other lowland Permo-Carboniferous localities. Their documentation increases both the dissorophoid diversity at Richards Spur and the faunal overlap between the tetrapod assemblage at Richards Spur and the classic early Permian localities of North America. Additional cranial and postcranial material is referred to $C$. morrisi, to a previously reported indeterminate dissorophine, and to $C$. woehri, the knowledge of which is greatly expanded through this report. Analysis of several osteoderm morphotypes using neutron tomography reveals information that both strengthens taxonomic referrals (e.g., bifurcated ventral flange in Dissorophus) and reveals unexpected new insights into dissorophid osteoderm variation (ventral flange of the internal series in Cacops; presence of an internal series in Aspidosaurus). The extensive diversity of terrestrial dissorophoids at this site is unparalleled and furthers the interpretation of the assemblage as a unique early Permian paleocommunity produced by distinct environmental conditions.
\end{abstract}

Bryan M. Gee. Department of Biology, University of Toronto Mississauga, 3359 Mississauga Road, ON L5L 1C6, Canada. bryan.gee@mail.utoronto.ca Joseph J. Bevitt. Australian Centre for Neutron Scattering, Australian Nuclear Science and Technology Organisation, New Illawara Road, Lucas Heights, NSW 2234, Australia. jbv@ansto.gov.au Robert R. Reisz. Department of Biology, University of Toronto Mississauga, 3359 Mississauga Road, ON L5L 1C6, Canada and International Centre of Future Science, Jilin University, 2699 Qianjin Street, Changchun, 130012, China. robert.reisz@utoronto.ca

Gee, Bryan M., Bevitt, Joseph J., and Reisz, Robert R. 2019. Dissorophid diversity at the early Permian cave system near Richards Spur, Oklahoma, USA. Palaeontologia Electronica 22.2.46A 1-32. https://doi.org/10.26879/976 palaeo-electronica.org/content/2019/2623-richards-spur-dissorophids 
GEE, BEVITT, \& REISZ : RICHARDS SPUR DISSOROPHIDS

Keywords: dissorophid; Permian; temnospondyl; Richards Spur; tomography

Submission: 1 March 2019. Acceptance: 3 June 2019.

\section{INTRODUCTION}

The early Permian karst system near Richards Spur, Oklahoma, preserves a diverse terrestrial tetrapod assemblage interpreted to have resided in an upland environment (MacDougall et al., 2017), physically separated from lowland floodplains that comprise the majority of early Permian terrestrial deposits in North America. As a result of the differing depositional environments, the Richards Spur locality captures an exceptionally diverse community of terrestrial tetrapods (>40 recognized species), including a number of endemic taxa and many small-bodied taxa that would normally be lost to hydrodynamic sorting in highenergy fluvial systems (MacDougall et al., 2017). Part of this assemblage is a diverse array of terrestrial dissorophoid temnospondyls, a clade that has long been of interest as putative stem lissamphibians (e.g., Bolt, 1969; Sigurdsen and Bolt, 2010; Sigurdsen and Green, 2011; Schoch, 2019) or as stem batrachians (e.g., Anderson et al., 2008b; Pardo et al., 2017). Among the Richards Spur dissorophoids are members of the Dissorophidae, a medium-sized clade with distinctive osteoderm morphotypes that is extensively documented from the Permo-Carboniferous of North America. The majority of the dissorophid fossil record comes from the Texas red beds (e.g., Williston, 1910a, 1910b; Carroll, 1964; Schoch, 2012; Schoch and Milner, 2014). The presence of dissorophids at the Richards Spur locality has been known for several decades (e.g., Bolt, 1974a, 1977; Sullivan et al., 2000), but much of this material was fragmentary or isolated and difficult to fully compare with other members of the clade from coeval localities. Following intensive collection and study in the twentyfirst century, the eucacopines Cacops morrisi (Reisz et al., 2009; Gee and Reisz, 2018a) and Cacops woehri (Fröbisch and Reisz, 2012; Fröbisch et al., 2015) are now well-known, established components of the locality. A more taxonomically ambiguous skeleton was described by Gee and Reisz (2018b) and identified as a dissorophine dissorophid distinct from Dissorophus and Broiliellus. Here we describe new dissorophid material from Richards Spur. This includes both material referable to the previously known taxa (C. morrisi, C. woehri, Dissorophinae indet.) and new, diagnos- tic material referable to Dissorophus and Aspidosaurus, two taxa not previously reported from this locality.

\section{METHODS}

ROMVP 80069, ROMVP 80076 and ROMVP 80078 were scanned via neutron tomography that was conducted using the DINGO thermal-neutron instrument located at the $20 \mathrm{MW}$ Open-Pool Australian Lightwater (OPAL) reactor housed at the Australian Nuclear Science and Technology Organisation (ANSTO), Lucas Heights, New South Wales, Australia (Garbe et al., 2015). Neutrons were converted to photons using a $100 \times 100 \times$ $0.03 \mathrm{~mm}$ Gadox scintillator screen $\left(\mathrm{Gd}_{2} \mathrm{O}_{2} \mathrm{~S}: \mathrm{Tb}\right.$, RC Tritec AG) and resultant photons detected by an Andor IKON-L CCD camera (liquid-cooled, 16bit, $2048 \times 2048$ pixels) coupled with a Makro Planar $100 \mathrm{~mm}$ Carl Zeiss lens to achieve a cubic voxel size of $45.5 \times 45.5 \times 45.5 \mathrm{~mm}$. A total of 1000 equally-spaced angle shadow-radiograph projections, each consisting of $3 \times 10$ second exposures, were obtained every $0.18^{\circ}$ as the sample was rotated over $180^{\circ}$ about its vertical axis. Both dark (closed shutter) and beam profile (open shutter) images were obtained for calibration before initiating shadow-radiograph acquisition. Data were reconstructed using Octopus Reconstruction v.8.8 (Inside Matters NV). The 16-bit TIFF data was downsampled in ImageJv.1.51h (National Institutes of Health) to improve computation time. Segmentation was performed in Avizo v.9.3.0 (FEl Visualization Sciences). The raw data is available upon reasonable request to the authors or to the Royal Ontario Museum, Vertebrate Paleontology (ROMVP) (copyright holder).

Manual preparation of $\mathrm{OMNH} 79338, \mathrm{OMNH}$ 79339, OMNH 79340 and OMNH 79340 was performed by BMG using air scribes and pin vises. All specimens come from the Dolese Brothers Limestone Quarry near Richards Spur, Oklahoma, USA. Figures were prepared using Adobe Illustrator and Photoshop Creative Cloud 2018.

\section{Institutional Abbreviations}

BMRP, Burpee Museum, Rockford, NJ; FMNH, Field Museum, Chicago, IL, USA; OMNH, Sam Noble Oklahoma Museum of Natural History, Nor- 
man, OK, USA; ROMVP, Royal Ontario Museum Vertebrate Paleontology, Toronto, ON, Canada; SMNS, Staatliches Museum für Naturkunde Stuttgart, Baden-Württemberg, Germany.

\section{Anatomical Abbreviations}

ahk, anterior humeral keel; art, articular; ang, angular; c, coronoid; ch, choana; cl, clavicle; cle, cleithrum; d, dentary; del, deltoid crest; ect, ectepicondyle; ectr, ectepicondylar ridge; ent, entepicondyle; entr, entepicondylar ridge; eo, exoccpital; f, frontal; fgl, supraglenoid foramen; gl, glenoid; ic, intercentrum; icl, interclavicle; inf, internarial fontanelle; j, jugal; I, lacrimal; lep, lateral exposure of palatine; $\mathbf{m}$, maxilla; $\mathbf{n}$, nasal; $\mathbf{n s , ~ n e u r a l ~ s p i n e ; ~}$ opi, opisthotic; os.e, external osteoderm; os.i, internal osteoderm; p, parietal; pal, palatine; pc, pleurocentrum; pec, attachment site for pectoralis muscle; pf, prefrontal; phr, proximal humeral ridge; pmx, premaxilla; po, postorbital; pof, postfrontal; pos, postsplenial; poz, postzygapophysis; pp, postparietal; pre, prearticular; pro, prootic; prz, prezygapophysis; psp, parasphenoid; pt, pterygoid; qj, quadratojugal; r, rib; sc, scapula; scl, sclerotic plate; sg, spinal groove; sgf, supraglenoid fossa; sp, splenial; sq, squamosal; ssf, subscapular fossa; st, supratemporal; stp, stapes; sur, surangular; $\mathbf{t}$, tabular; tp, transverse process; $\mathbf{v}$, vomer; ver, ventral ectepicondylar ridge; vf, ventral flange.

\section{SYSTEMATIC PALEONTOLOGY}

Order TEMNOSPONDYLI Zittel, 1888

Superfamily DISSOROPHOIDEA Bolt, 1969

Unranked clade OLSONIFORMES Anderson,

Henrici, Sumida, Martens, and Berman, 2008a

Family DISSOROPHIDAE Boulenger, 1902

Referred material. OMNH 79340, partial skull with right mandible (Figure 1).

Description and comparison. OMNH 79340 is a partial skull found on a large multitaxic block that also preserves a complete skull of Cacops morrisi (OMNH 79339, see below) (Figure 1). It is sheared horizontally at the level of the palate and only a few fragments of the lateral elements of the skull roof (lateral exposure of the palatine [LEP], maxilla, quadratojugal) and portions of the palate (parasphenoid, pterygoids) are preserved. The contour of the specimen remains sufficiently well-defined to approximate its length $(7.8 \mathrm{~cm}$ from the posterior margin of the quadrate to the approximate anterior symphysial margin). This measurement would overestimate the length in relation to past measurements (premaxilla to posterior skull margin) by $0.7-1.8 \mathrm{~cm}$ (based on measurements of relatively small, complete skulls [Appendices 1, 2, 3]).

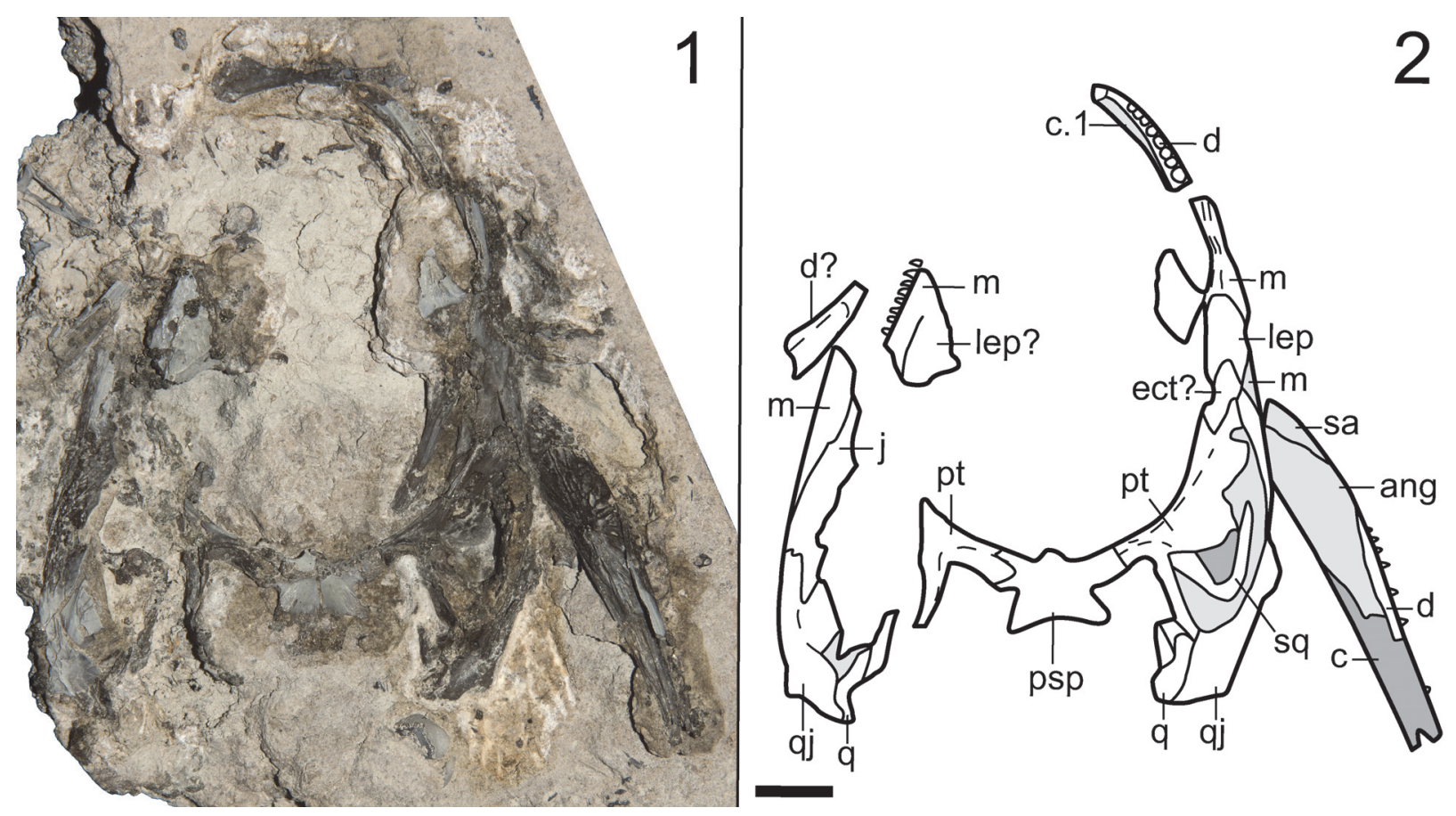

FIGURE 1. Partial skull of new referred specimen of Olsoniformes indet., OMNH 79340, in dorsal profile. 1, photograph; 2, line drawing. Scale bar equals $1 \mathrm{~cm}$. 
OMNH 79340 is thus better approximated to a maximum skull roof length between 6.0 and 6.9 $\mathrm{cm}$, which brackets the holotype of Cacops woehri $(6.2 \mathrm{~cm})$. The ornamentation consists of faint ridging on the maxilla and a fragment representing a probable LEP. The transverse flange of the pterygoid can be seen to descend below the level of the palate. The basal plate of the parasphenoid is a transversely elongate rectangle. Two fragments of the right mandible are present, the anterior region of the dentary (nine tooth positions) in articulation with the skull roof and the angular and posterior dentary ( $>10$ tooth positions) exposed labially and dislodged and rotated adjacent to the skull. Ornamentation on the fragmentary mandible consists primarily of ridges similar to the skull. A tooth count estimate cannot be derived from these fragments.

Identification. OMNH 79340 is identified as an olsoniform temnospondyl based on the type of ornamentation on the few cranial elements, its large size relative to co-occurring amphibamiforms and the ventrolateral angling of the transverse flange of the pterygoid. It is subsequently distinguished from the co-occurring trematopid Acheloma dunni by the preservation of a large lateral exposure of the palatine (LEP) dorsal to the maxilla (Figure 1) and by the ornamentation of this suborbital region, which consists of shallow ridges (as in Cacops morrisi and Cacops woehri [Reisz et al., 2009; Fröbisch and Reisz, 2012]) and not the circular pits found in comparably sized trematopids (e.g., Polley and Reisz, 2011). The contours indicate a long and relatively slender skull, more like that of Cacops (Williston, 1910a; Reisz et al., 2009) and Aspidosaurus (Broili, 1904; Berman and Lucas, 2003) than that of Dissorophus (Williston, 1910b; DeMar, 1968). The marginal teeth of the maxilla are modestly small and non-recurved, as in C. woehri (Fröbisch and Reisz, 2012). Conversely, the basal plate of the parasphenoid is a transversely elongate rectangle, as in the smallest specimen of C. morrisi (Reisz et al., 2009) and larger specimens of $C$. woehri (Fröbisch and Reisz, 2012), although it is only exposed in dorsal profile. The ornamentation is closer to that of $C$. woehri in comprising shallow ridges, although this feature is also similar to that in the suborbital region of small specimens of $C$. morrisi.

\section{Subfamily EUCACOPINAE sensu Schoch and Milner, 2014 CACOPS Williston, 1910a}

Type species. Cacops aspidephorus Williston, $1910 a$, by original designation
Referred material. ROMVP 80078 , isolated neural arch and spine with articulated osteoderm (Figure 2.1-3, 2.5-7, 2.9.11); ROMVP 80079, isolated neural arch and spine (Figure 2.4, 2.8); OMNH 79341, isolated right scapula (Figure 3).

Description and comparison. ROMVP 80078 is a large neural arch and spine with an articulated internal osteoderm (Figure 2.1-2.3, 2.5-2.7, 2.9.211). The neural spine is proportionately tall and fused to the osteoderm, although the suture between the elements remains distinct. The neural arch of ROMVP 80079 is only slightly shorter than the neural arch of ROMVP 80078 (Figure 2.4, 2.8), but the disparity in neural spine height is quite noticeable; ROMVP 80079 is approximately half as tall as ROMVP 80078. Transverse ridges that extend down the sides of the neural spine are found in both specimens and produce the crossshaped contour in dorsal profile that was previously noted by Gee and Reisz (2018a). The transverse processes of ROMVP 80079 are not as laterally extensive. The dorsal surface of ROMVP 80079 bears a noticeable, deep anteroposterior groove. The same feature was revealed in ROMVP 80078 through the CT analysis (Figure 2.10) into which a ventral flange of the internal osteoderm inserts (Figure 2.11). The groove does not meet the anterior or posterior surfaces of the neural spine. The osteoderm of ROMVP 80078 is slightly sculptured and with a few pits. It is distinctly wider than the neural spine, reflecting both a more anterior position and ontogenetic maturity.

OMNH 79341 is a large, mostly complete right scapula (Figure 3 ). A thin fragmentary ossification lies along the ventral margin of the scapula, but it cannot be strongly associated with a coracoid and appears to be distinct from the scapula. Faint striations are present along the dorsal half of the lateral surface. Measured along the lateral surface, OMNH 79341 is $5.7 \mathrm{~cm}$ in height, compared to 4.7 $\mathrm{cm}$ in OMNH 79339 and $4.5 \mathrm{~cm}$ in OMNH 73206a. Identification. These specimens are referred to the genus because they are identical to those known from Cacops morrisi. The presence of a flange on the internal (rather than the external) osteoderm in ROMVP 80078 is a previously unreported feature in Cacops and is commented on in greater detail in the discussion. The internal osteoderms of large specimens are often preserved in articulation with the neural spine, and the presence of this flange is not contrary to the formal diagnosis of Cacops (e.g., Reisz et al., 2009; Fröbisch and Reisz, 2012; Schoch and Milner, 2014). Therefore, we attribute its novel presence to preservational 

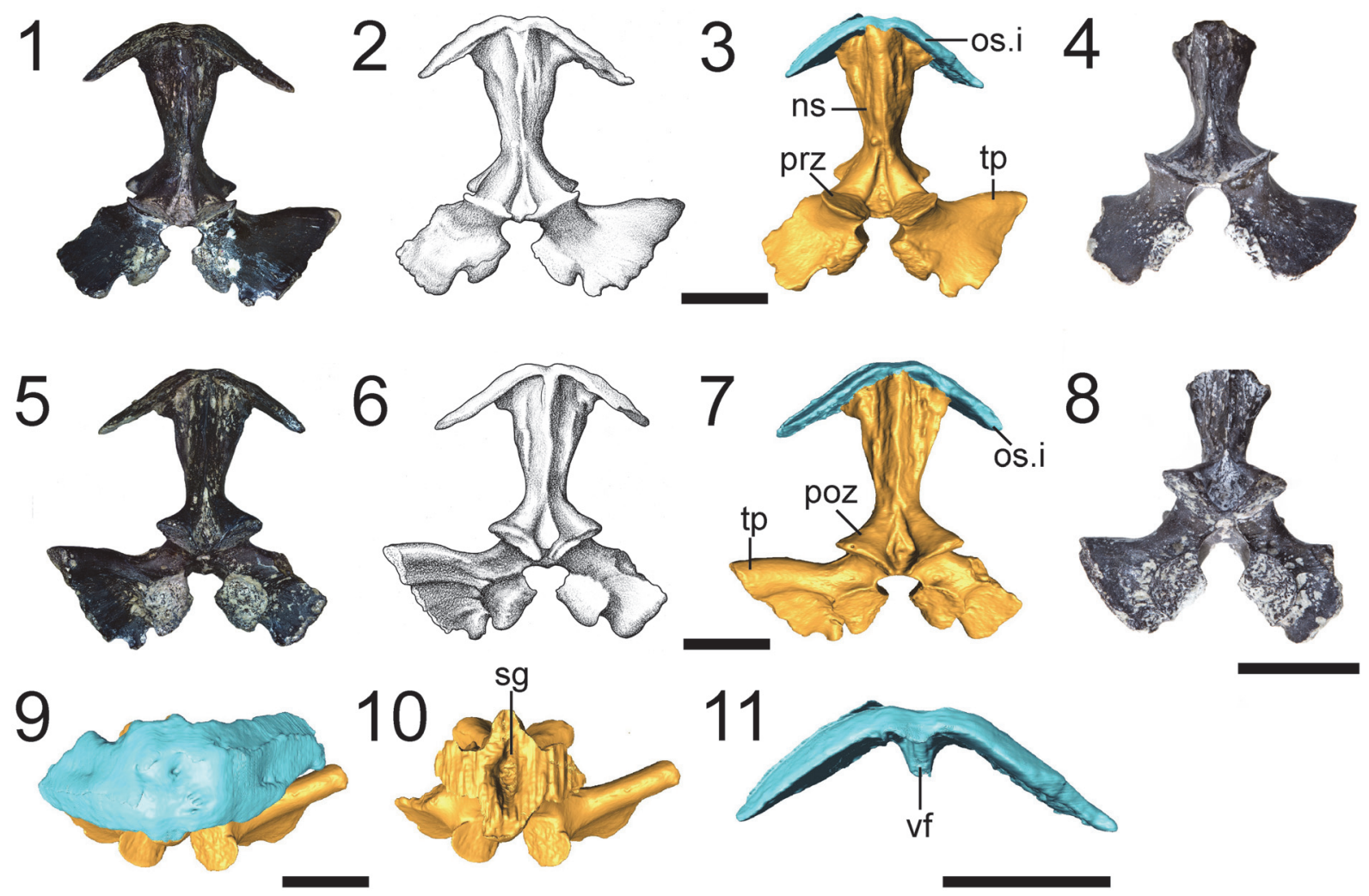

FIGURE 2. Isolated vertebral material of new referred specimens of Cacops sp. 1, photograph of ROMVP 80078 (neural spine with internal osteoderm) in anterior profile; 2, illustration of the same; 3, segmented rendering of the same; 4, photograph of ROMVP 80079 (neural spine) in anterior profile; 5, photograph of ROMVP 80078 in posterior profile; $\mathbf{6}$, illustration of the same; $\mathbf{7}$, segmented rendering of the same; $\mathbf{8}$, photograph of ROMVP 80079 in posterior profile; 9 , segmented rendering of ROMVP 80078 in dorsal profile; 10, the same with the osteoderm removed to show the spinal groove (sg); 11, segmented rendering of the osteoderm of ROMVP 80078 in anterior profile. Scale bars equal $1 \mathrm{~cm}$.

tendencies (i.e., that the flange is obscured when the neural spine-osteoderm articulation is intact and may break off when disarticulated) rather than to taxonomic differentiation. OMNH 79341 is larger than any scapula described for $C$. morrisi (Gee and Reisz, 2018a; this study [OMNH 79339, see below]) but is otherwise identical to previous reports. The same is true of ROMVP 80078, which is about $15 \%$ taller than the largest previously reported neural spines (those overlying $\mathrm{OMNH}$ 73206c [Gee and Reisz, 2018a]). The osteoderm is relatively broad, likely reflecting both ontogeny and anterior axial position. Without any knowledge on the postcrania of Cacops woehri, a species-level assignment cannot be confidently made.

Cacops morrisi Reisz, Schoch and Anderson, 2009 sensu Gee and Reisz, 2018a

Referred material. OMNH 79339 (Figure 4), complete skull with associated mandibles and anterior postcranial elements (osteoderms, vertebrae, pectoral girdle).

Description and comparison. OMNH 79339 is a complete skull, exposed in dorsal profile, that is referred to Cacops morrisi; the palate is obscured, and the occiput is either dislodged or obscured (Figure 4). The skull is nearly identical in size to a previously described specimen (OMNH 73206a) (Appendix 1) and is of an intermediate size within the existing range of specimens of this taxon. The skull roof has been fractured in a few places, with loss of the lateral surface of the left temporal region and much of the right posterolateral roof. Due to preexisting damage and heavy pyritization of much of the skull roof, few of the sutures can be defined. Ontogenetically influenced features conform to the predicted patterns based on the specimen's size: 1) presence of a lateral exposure of the palatine (LEP) and absence of a lateral exposure of the ectopterygoid (LEE); 2) development of pro- 


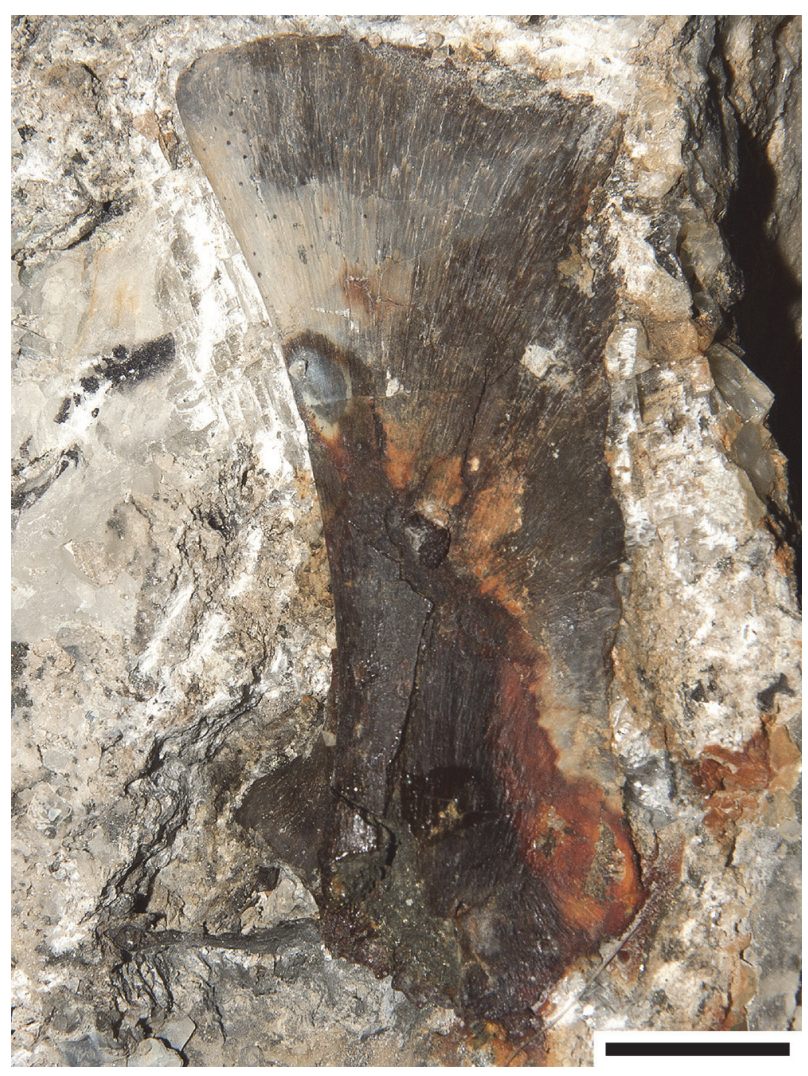

FIGURE 3. Photograph of right scapula of new referred specimen of Cacops sp., OMNH 79341, in lateral profile. Scale bar equals $1 \mathrm{~cm}$.

nounced tubercles, particularly on the posterior cranial elements; and 3) a tabular horn that closely approaches the dorsal process of the quadrate.

The most important part of OMNH 79339 is the pair of nearly complete mandibles (Figures 4, 5 ). The left mandible is oriented upright and is damaged posteriorly in the adductor chamber. At least 40 tooth positions with alternating replacement are identified on this mandible. A large fang is positioned lingual to the fourth position and is mostly directed horizontally. It cannot be discerned whether this is a discrete adsymphyseal ossification, as reported for Cacops aspidephorus by Anderson (2005). Ornamentation of the labial and ventral surfaces comprises coarse pitting and a few ridges and tubercles, similar to the skull roof. The right mandible is complete and exposed in lingual profile (Figure 5). The general sutural patterns are similar to those previously reported for dissorophids (e.g., Anderson, 2005; Holmes et al., 2013; Liu, 2018). For example, the postsplenial tapers to a point just past the level of the anterior margin of the adductor chamber, and there are three coronoids covered in denticles. The lingual surface has been crushed into the adductor chamber, obscuring any potential Meckelian foramen, but it forms a low wall, similar to Anakamacops petrolicus (Liu, 2018). The coronoid process is low, as hypothesized by Gee and Reisz (2018a) based on a partially exposed mandible of Cacops morrisi, and it is framed lingually by the third (posteriormost) coronoid anteriorly and by the surangular posteriorly.

Semi-articulated postcranial elements include the pectoral girdle (scapula, interclavicle, clavicle, cleithrum), partial humeri, trunk vertebrae, ribs and osteoderms (Figure 4). These do not contribute much new information either, as OMNH 73206a was articulated with more substantial and better preserved postcrania (Gee and Reisz, 2018a). The only apparent difference between these specimens is a minor and gradational difference in the development of ornamentation of the osteoderms. The dorsal surface in OMNH 79339 is slightly smoother and with a few small pits compared to $\mathrm{OMNH}$ 73206a (Gee and Reisz, 2018a).

Identification. Despite being partially damaged postmortem, numerous features identify $\mathrm{OMNH}$ 79339 as an individual of Cacops morrisi, including (but not limited to): 1) development of rugose ornamentation with tubercles; 2) more open otic notch compared to Cacops woehri; and 3) the absence of a narrow, elevated circumorbital rim.

\section{Cacops woehri Fröbisch and Reisz, 2012, sensu Fröbisch, Brar and Reisz 2015}

Referred material. OMNH 79338, partial skull (Figures 6, 7); ROMVP 80080, partial snout (Figure 8.1-4); ROMVP 80081, partial snout (Figure 8.5-8); ROMVP 80082, partial otic notch (Figure 9.1-6); ROMVP 80083, partial left jaw articulation (Figure 9.7-14).

Description and comparison. OMNH 79338 is a partial skull, also exposed in dorsal profile (Figure $6)$. It is larger than the holotype $(8.4 \mathrm{~cm}$ in skull roof length vs. $6.2 \mathrm{~cm}$ in the holotype) and essentially the same size as a previously referred specimen (BMRP 2007.3.5) (Appendix 3). The skull is split perfectly down the midline, with the right side being preserved (Figure 6). Only the quadrate and the margins of the posterolateral elements (tabular, quadratojugal) have been lost. The sutural patterns are the same as in the holotype, with the exception of a maxilla that is clearly excluded from the orbit (Figures 6, 7). OMNH 79338 conforms well to ontogenetic changes described by Fröbisch et al. (2015), such as increased size of the occipital flange, little change in the development of the ornamentation and the absence of a long ventral process of the postorbital. 

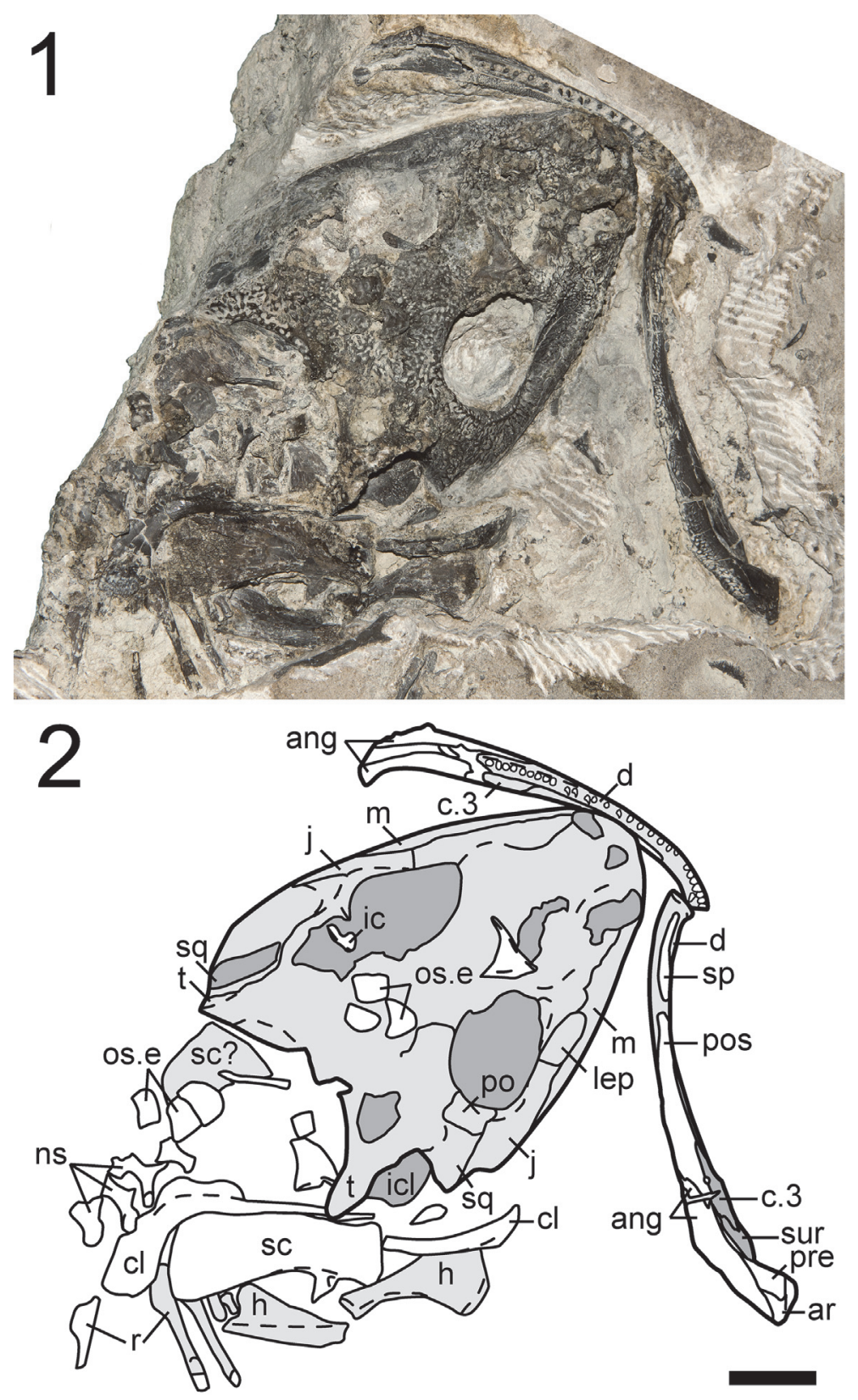

FIGURE 4. Skull and associated postcrania of new referred specimen of Cacops morrisi, OMNH 79339, in dorsal profile. 1, photograph; 2, line drawing. Only elements belonging to the dissorophid are illustrated in part 2 . Scale bar equals $1 \mathrm{~cm}$.

ROMVP 80080 and ROMVP 80081 are partial snouts, both broken just posterior to the choana (Figure 8). ROMVP 80080 preserves a median depression on the underside of the tip of the snout (the intervomerine fontanelle). Development of this fontanelle is often correlated with the presence of an internarial fontanelle on the skull roof between the premaxillae, which is preserved in ROMVP 80081 (Figure 8.5-6). Incompleteness of other specimens of Cacops woehri has previously pre- vented a characterization of this region, but it is here shown to be only slightly smaller than that of Cacops morrisi (previously considered to be much smaller in a diagnostic fashion). The palatal dentition of ROMVP 80080 is well-exposed and preserves the usual covering of the palate by denticles, including on the rim of the choana and extending onto the dorsal surface of the vomer. Paired vomerine tusks are preserved at the antero- 


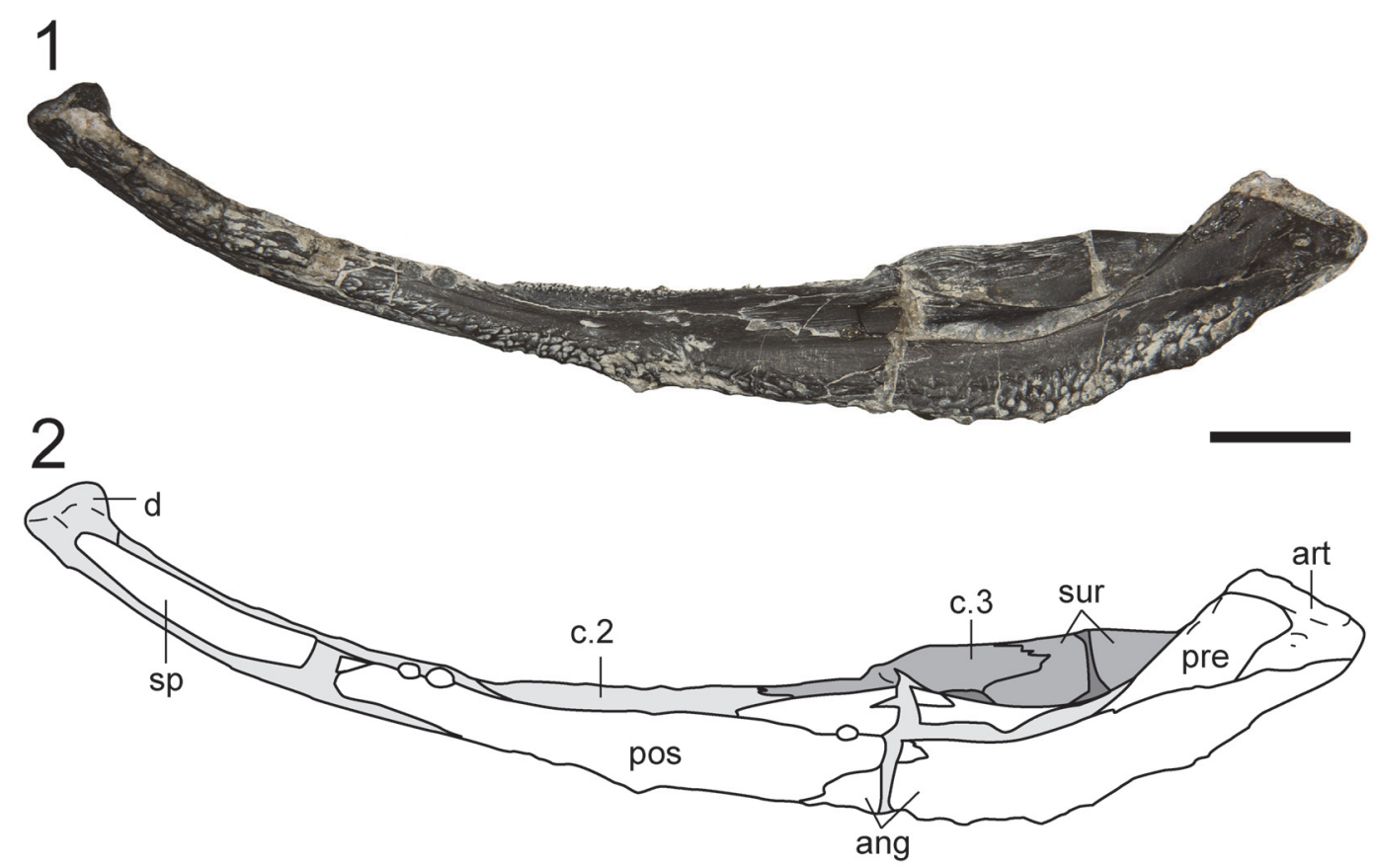

FIGURE 5. Right mandible of new referred specimen of Cacops morrisi, OMNH 79339, in lingual profile. 1, photograph; 2, line drawing. Scale bar equals $1 \mathrm{~cm}$.

medial corner of the choana (Figure 8.3-4), a feature not previously identified in Cacops woehri.

ROMVP 80082 is a partial right otic notch with an articulated stapes (Figure 9.1-6). The otic notch is markedly constricted by the flanks of the supratympanic flange, particularly by a ventral expansion of the dorsal flank (Figure 9.3, 9.6), in contrast to Cacops morrisi in which it is more open. The stapes extends through the opening and beyond the vertical plane of the supratympanic flange. It is flat and narrow distally and expanded into a more circular footplate posteriorly. A small depression at the base may represent a stapedial foramen. The ventral flank of the supratympanic flange extends medially to overlap with the ascending flange of the quadrate ramus of the pterygoid. The otic capsule is partially preserved, with discrete prootic and opisthotic ossifications (Figure 9.1). Ornamentation of the skull roof is like that of other specimens of Cacops woehri (Figure 9.2, 9.5). The occipital flange is large and shallowly slopes ventrally from the posterior skull table.

ROMVP 80083 is a partial left jaw articulation comprised mostly of the quadrate and the articular (Figure 9.7-14). The lateral condyle is more ventrally positioned, producing a concave articular surface that is angled ventromedially (Figure 9.7, 9.11). The posteriormost portion of the quadratojugal overlaps the quadrate, with a short process that extends partially up the lateral surface of the dorsal process (Figure 9.9, 9.13). The lateral edge of the quadratojugal is ornamented with a few large pits. The dorsal process is short anteroposteriorly and dorsoventrally and only slightly expands along its height.

Identification. OMNH 79338 can be readily distinguished from Cacops morrisi based on features including (but not limited to): 1) the less developed ornamentation, consisting primarily of shallow ridges; 2) narrowly constricted otic notch; 3 ) maxillary tooth row that extends past the posterior orbital margin; and 4) proportionately large occipital flanges extending at a shallower angle from the skull roof (Figures 6,7 ). One feature distinguishes OMNH 79338 from the holotype of Cacops woehri - a maxilla excluded from the orbit, which was used to distinguish it from Cacops morrisi (Fröbisch and Reisz, 2012). There is no clear evidence showing either damage or dislodgement in either specimen that would account for this disparity, and in all other respects, OMNH 79338 closely fits the description of Cacops woehri. OMNH 79338 is much larger than the holotype (OMNH 73216) (Appendix 3). Accordingly, this observation suggests that there may be an ontogenetic shift in the sutural relationships of the suborbital elements, rather than a third eucacopine at Richards Spur.

ROMVP 80080 and ROMVP 80081 are referred on the basis of the ornamentation (Figure $8.1,8.5)$, which consists only of shallow ridges 

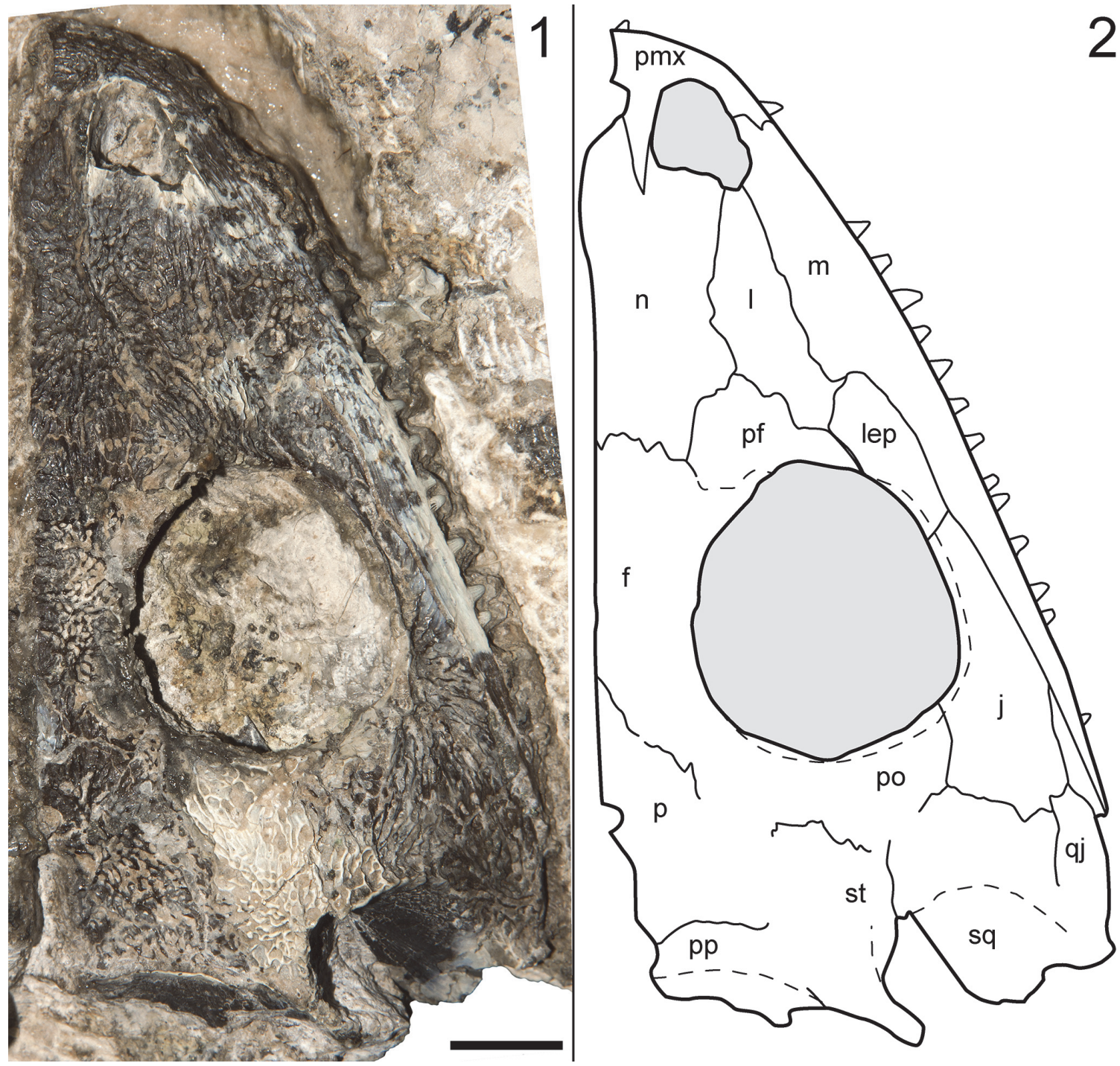

FIGURE 6. Skull of new referred specimen of Cacops woehri, OMNH 79338, in dorsal profile. 1, photograph; 2, line drawing. Scale bar equals $1 \mathrm{~cm}$.

despite overlapping in size with some specimens of Cacops morrisi. Based on the size of the external nares (the only feature sufficient for making size comparisons), they were slightly smaller individuals than OMNH 79338. The nature of the internarial fontanelle (if present) was previously not determinable in Cacops woehri such that its characterization here (based on ROMVP 80081) as being comparably large to that of $C$. morrisi is not evidence against our referral. ROMVP 80082 is referred to $C$. morrisi on the basis of the same type of ornamentation on the skull roof elements and the narrow constriction of the otic notch (Figure 9.2-3).

ROMVP 80083 is identified as an olsoniform (cf. Cacops woehri) based on the development of the dorsal process of the quadrate and its relative size compared to amphibamiforms. The morphology is most comparable to that of Cacops (e.g., Bolt, 1977; Reisz et al., 2009; Gee and Reisz, 2018a), with a transversely flattened dorsal process, compared to Dissorophus in which the process is a slender spike (e.g., DeMar, 1968; Milner, 2003). However, there are some notable differences from the quadrate of Cacops morrisi. The dorsal process in ROMVP 80083 barely expands anteroposteriorly (Figure 9.9-10), whereas in specimens of C. morrisi (Reisz et al., 2009; Gee and Reisz, 2018a; this study), the dorsal process is greatly expanded. The ornamentation on the angular (Figure 9.9) consists of shallow ridges that are like those in C. woehri, in contrast to the circular 

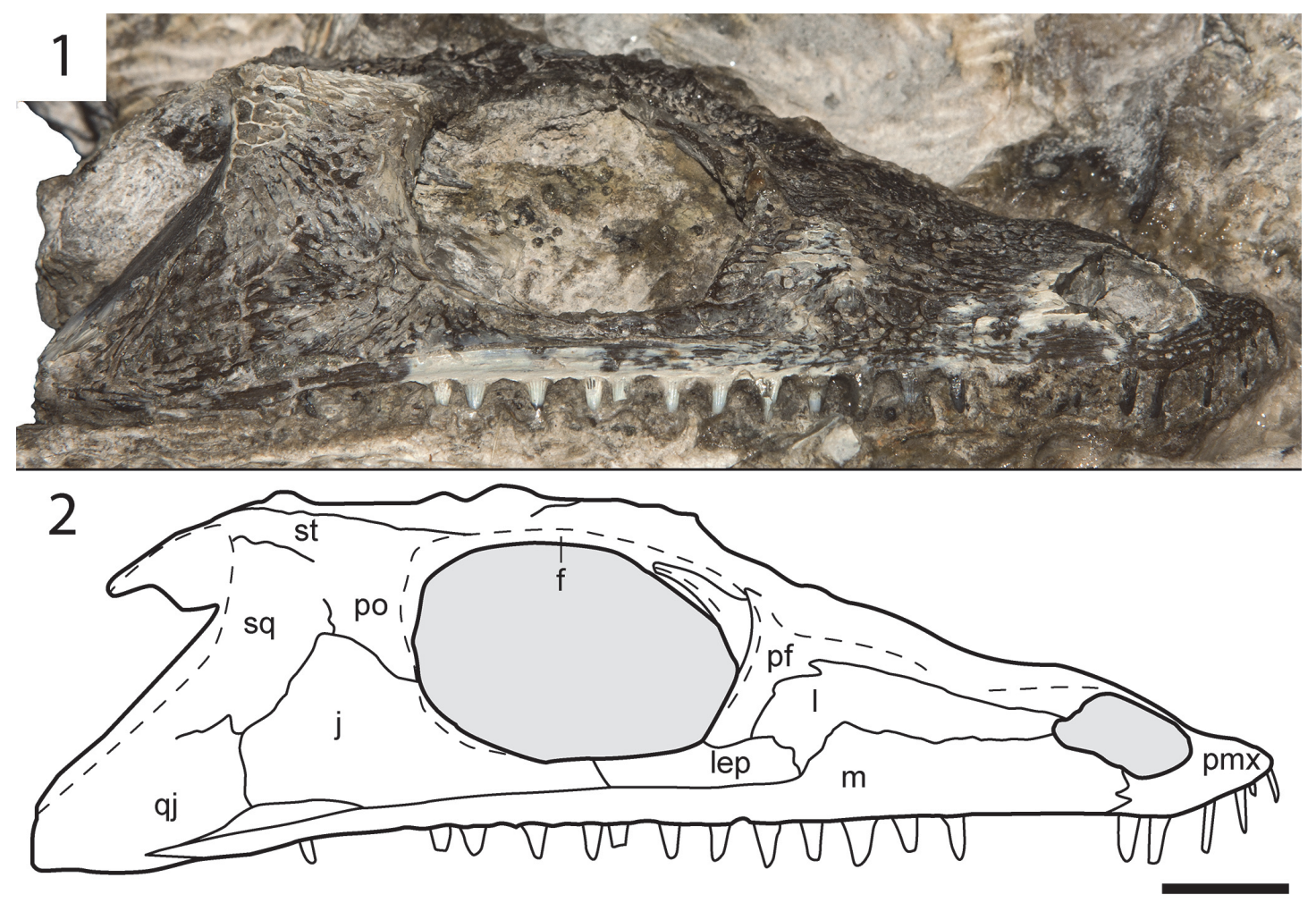

FIGURE 7. Skull of new referred specimen of Cacops woehri, OMNH 79338, in lateral profile. 1, photograph; 2, line drawing. Scale bar equals $1 \mathrm{~cm}$.

pitting found in C. morrisi (Gee and Reisz, 2018). The identification is provisional because the quadrate and mandible are presently unknown in $C$. woehri and because ROMVP 80083 does not preserve any autapomorphies for proper referral to this taxon.

\section{Subfamily ASPIDOSAURINAE sensu Schoch and Milner, 2014 \\ cf. ASPIDOSAURUS Broili, 1904 sensu Gee, 2018}

Type species. Aspidosaurus chiton Broili, 1904, by original designation

Referred material. ROMVP 80069 (Figures 10, 11 ), isolated pair of neural spines corresponding internal osteoderms and three articulated external osteoderms.

Description and comparison. ROMVP 80069 consists of an articulated series of two neural spines and their corresponding osteoderms (Figure 10). The neural spines are broken off at the level of the zygapophyses. Dorsally, they are transversely expanded where they contact the osteoderms, forming an oval contour when viewed in dorsal or ventral profile (Figure 10.10-12). The anterior and posterior faces of the neural spines are marked by striations (Figure 10.4-5). The osteoderms are subrectangular, being slightly wider transversely than anteroposteriorly long. Upon initial inspection, only a single series appears present in dorsal view, and the osteoderms are slightly angled to form an imbricated series, with posteroventral overlap along an anteromedially curved contact (Figure 10.7-9). Each osteoderm is ornamented by subcircular pitting. In ventral profile, another flat ossification is clearly present, separating each external ornamented osteoderm from the neural spine (Figure 10.10-12). CT data reveal that this ossification is closely associated with the neural spine, and although it forms a confluent dorsal surface with the external osteoderm, it is suturally distinct from the external-most ornamented surface (Figure 11.2-3). Comparisons with ROMVP 80078 (Cacops sp. neural spine and internal osteoderm) reveal a similar distinct separation between the neural spine and the osteoderm (Figure 11.5-6), although without any ventral flange. Based on the available data, we interpret this ossification as an internal osteoderm. The dorsal tips and the dorsolateral surfaces of the neural spines are tightly associated with the internal osteoderms, but they are unfused as revealed through the CT data (Figure 11.2-3). A gap infilled by matrix separates the tip of the neural 

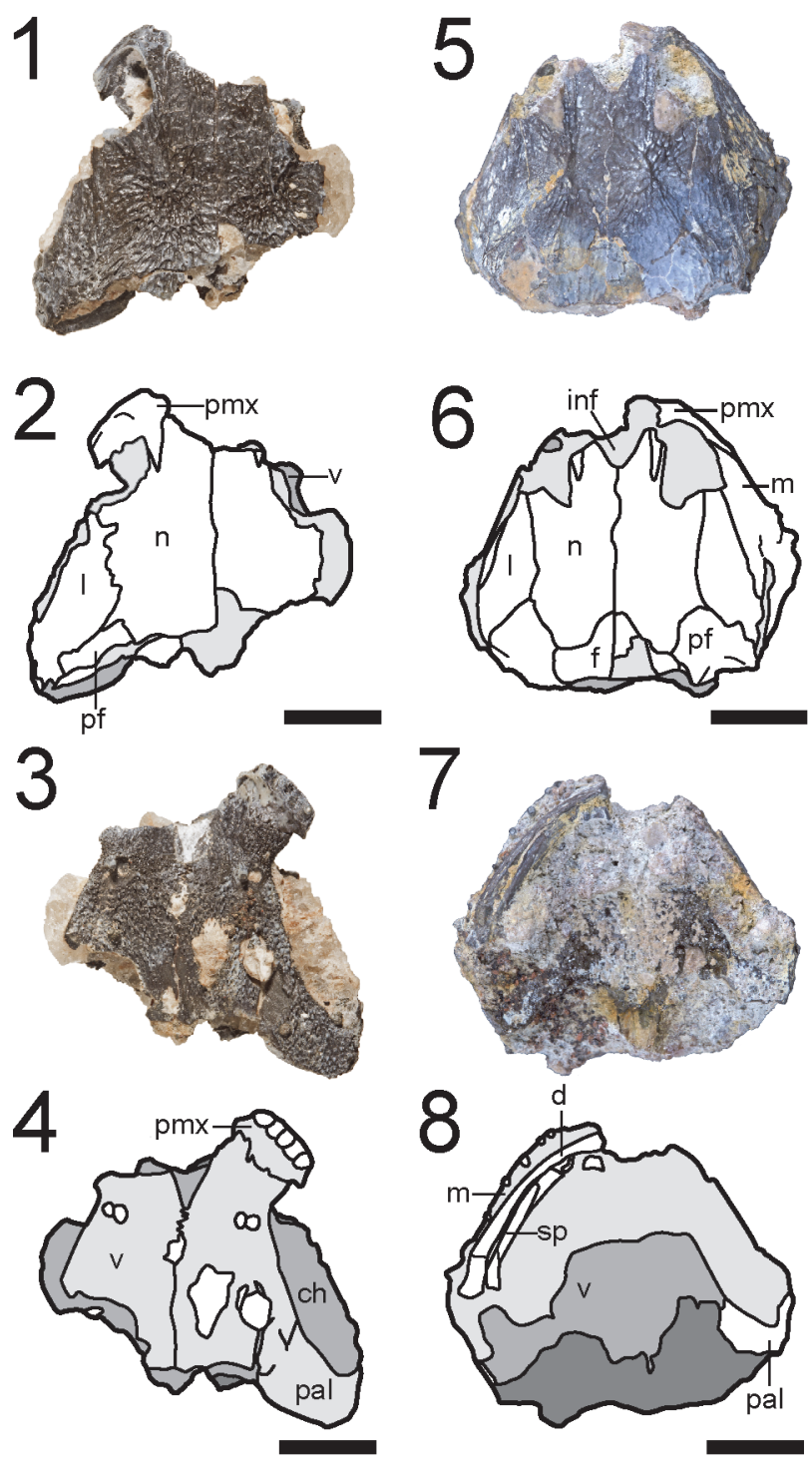

FIGURE 8. Partial snouts of new referred specimens of Cacops woehri, ROMVP 80800 and ROMVP 80081. 1, photograph of ROMVP 80800 in dorsal profile; 2, line drawing of the same; 3, photograph of ROMVP 80080 in ventral profile; 4, line drawing of the same; 5, photograph of ROMVP 80081 in dorsal profile; 6 , line drawing of the same; 7 , photograph of ROMVP 80081 in ventral profile; 8 , line drawing of the same. Scale bars equal $1 \mathrm{~cm}$.

spine from the internal osteoderm except at the edges (Figures 10.4-6, 11.2).

Identification. Prior to the identification of an internal series, ROMVP 80069 met all the criteria historically considered to be characteristic for Aspidosaurus, such as transverse expansion of the neural spine dorsally to create a "swollen" profile and a single series of osteoderms with a dorsal apex and ventrolaterally descending lateral flanks. The ornamentation is also very similar to that of Aspidosaurus (e.g., Broili, 1904; DeMar, 1966; Berman and Lucas, 2003; May et al., 2011). However, the external ventral view and the tomographic data clearly reveal the presence of an internal osteoderm. If we adhere to Schoch and Milner's diagnosis (2014), this specimen cannot be properly referred to Aspidosaurus because it possesses a double series of osteoderms.

Regardless of the validity of the various lesser known species of Aspidosaurus (e.g., Aspidosaurus crucifer), most material referred to the genus consists of isolated neural spines and osteoderms. There is a wide range of variation among this material, with most specimens previously referred to Aspidosaurus sharing the putative presence of a single series of transversely short, ovoid osteo- 

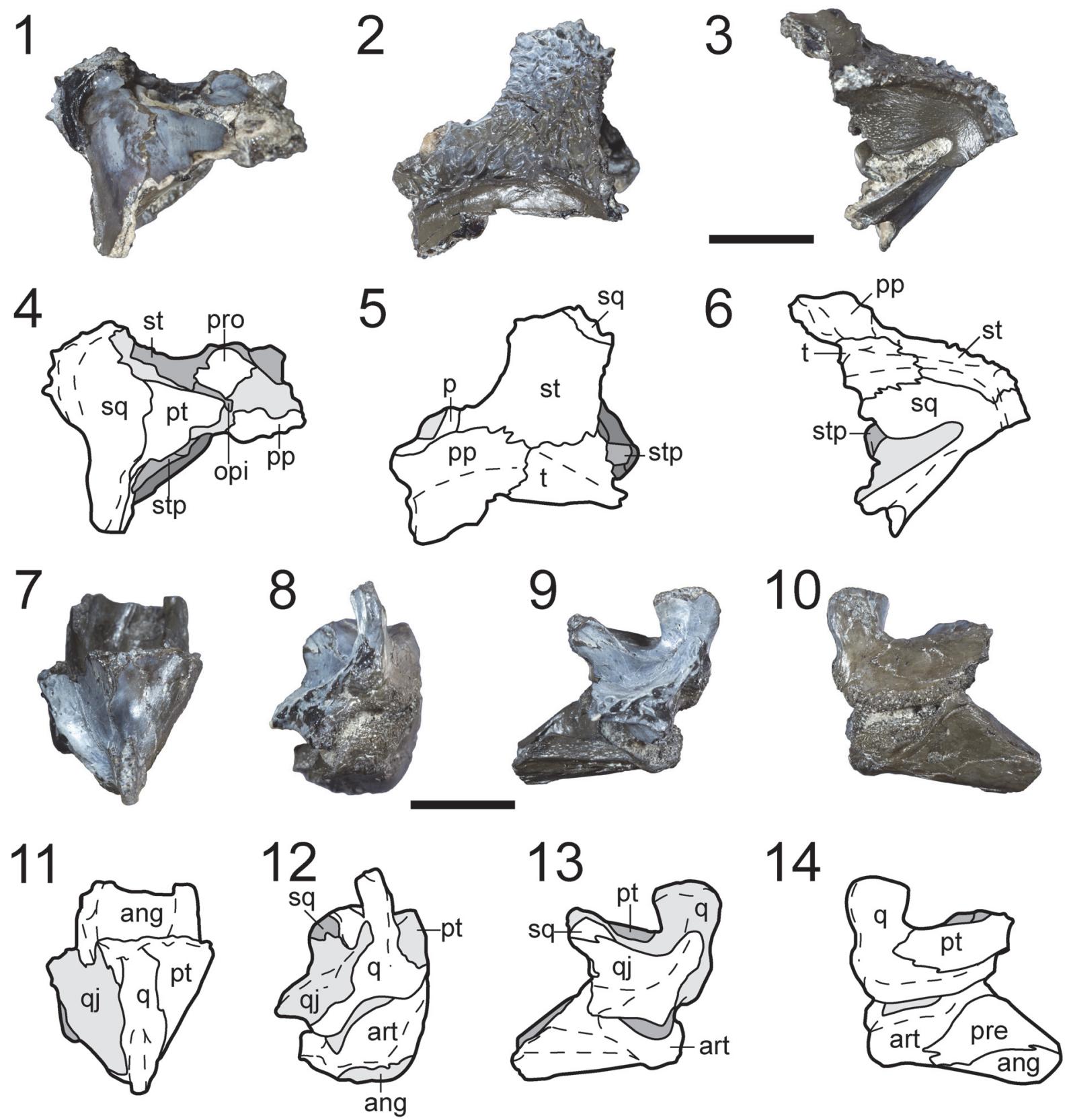

FIGURE 9. Cranial fragments of new referred specimens of Cacops woehri, ROMVP 80082 and ROMVP 80083.1 , photograph of ROM VP 80082 in anteroventral profile; 2 , the same in dorsal profile; 3 , the same in right lateral profile; 4, line drawing of ROMVP 80082 in anteroventral profile; 5 , the same in dorsal profile; $\mathbf{6}$, the same in right lateral profile; 7, photograph of ROMVP 80083 in dorsal profile; 8 , the same in posterior profile; $\mathbf{9}$, the same in left lateral profile; 10, the same in medial profile; 11, line drawing of ROMVP 80083 in dorsal profile; 12, the same in posterior profile; 13, the same in left lateral profile; 14, the same in medial profile. Scale bars equal to $1 \mathrm{~cm}$.

derms with an inverted-V morphology. However, some have a very steep and sharp apex that produces concave lateral surfaces (e.g., "Aspidosaurus crucifer" [Aspidosaurinae indet. according to Schoch and Milner, 2014]), whereas others have a gradual apex with flat lateral surfaces (e.g., Aspi- dosaurus chiton [Broili, 1904]; ROMVP 80069 [this study]). Some of the neural spines and osteoderms of Aspidosaurus binasser are even more disparate, closely resembling platyhystricine neural spines in being tall and transversely compressed (Berman and Lucas, 2003). Collectively, these observations 

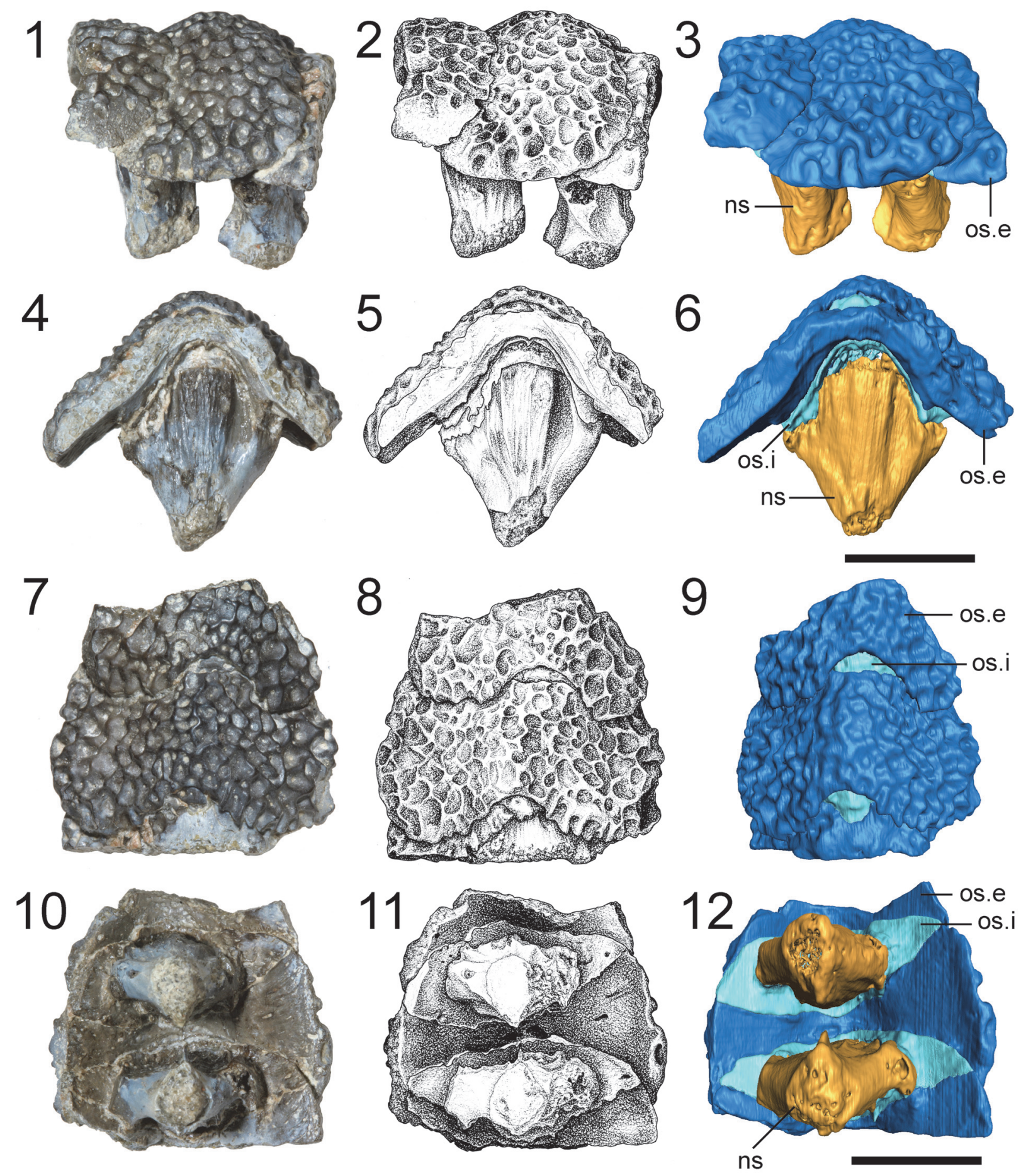

FIGURE 10. Osteoderms and neural spines of new referred specimen of Aspidosaurus sp., ROMVP 80069. 1, photograph in right lateral profile; 2 , illustration of the same; 3, segmented rendering of the same; $\mathbf{4}$, photograph in anterior profile; $\mathbf{5}$, illustration of the same; $\mathbf{6}$, segmented rendering of the same; $\mathbf{7}$, photograph in dorsal profile; $\mathbf{8}$, line drawing of the same; 9 , segmented rendering of the same; 10, photograph in ventral profile; 11, line drawing of the same; 12 , segmented rendering of the same. Scale bars equal $1 \mathrm{~cm}$. 

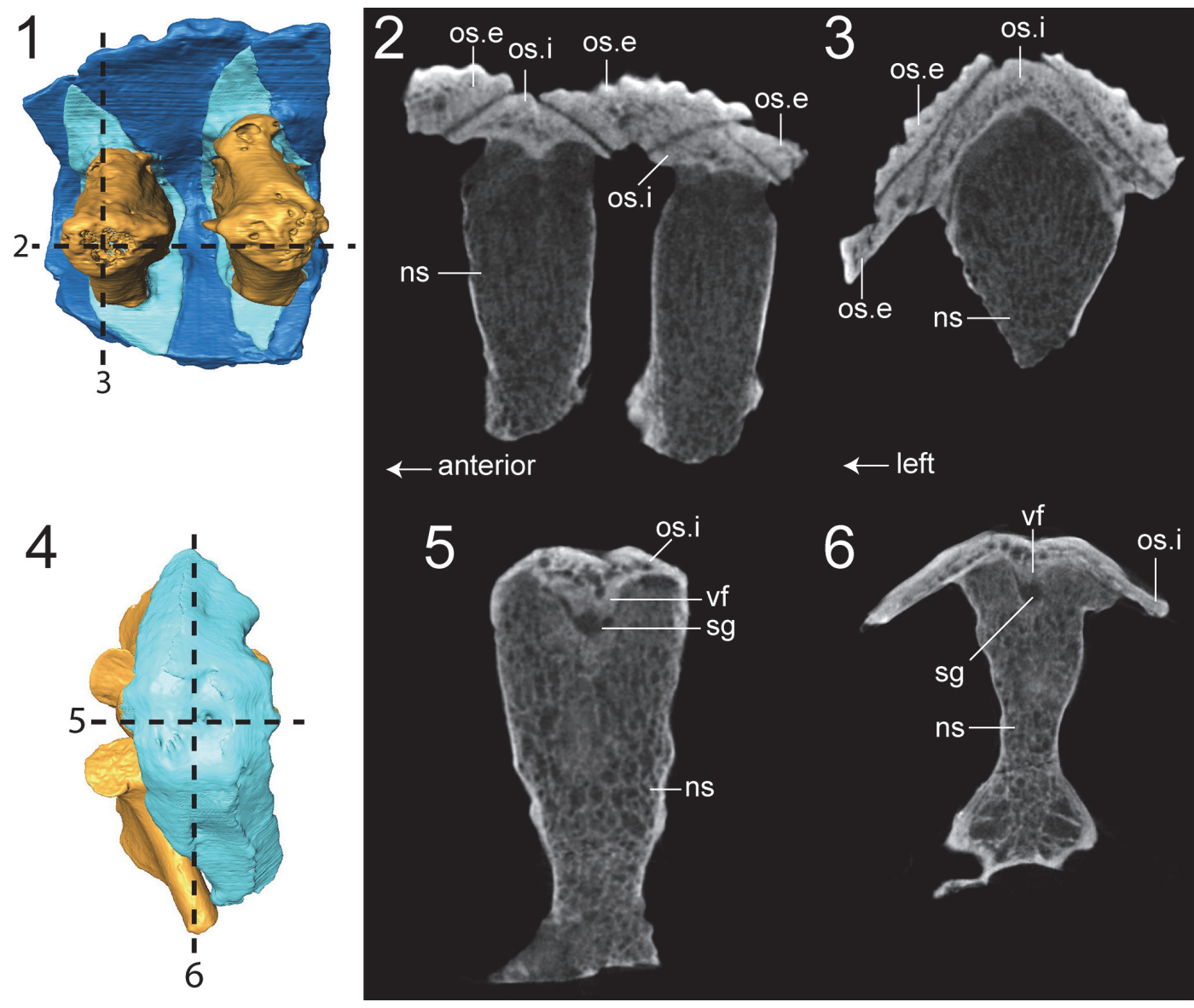

FIGURE 11. Comparison of osteoderms and neural spines of new referred specimen of Aspidosaurus sp., ROMVP 80069, and new referred specimen of Cacops sp., ROMVP 80078. 1, Segmented rendering in ventral profile showing planes of digital sections; 2, sagittal section; 3, transverse section; 4, segmented rendering of ROMVP 80078 in dorsal profile showing planes of digital sections; $\mathbf{5}$, sagittal section; $\mathbf{6}$, transverse section; note that a small portion of the transvere process was removed for spacing and because it does not contribute information regarding the osteodermspine contact.

reinforce arguments by previous workers (e.g., Schoch and Milner, 2014) that Aspidosaurus represents a "dumping ground" for isolated osteoderms and neural spines that more closely resemble the osteoderms of $A$. chiton than any other known dissorophid.

Among dissorophids, ROMVP 80069 most closely resembles the osteoderms of the now lost genotype, Aspidosaurus chiton, (Broili, 1904, table 6) and Alegeinosaurus aphthitos, which Gee (2018) synonymized with Aspidosaurus. Both As. chiton and Al. aphthitos are known from partial strings of vertebrae and osteoderms, which reveal the following similarities to ROMVP 80069: 1) transverse expansion of the neural spine dorsally; 2) osteoderms of subequal length and width; 3) gently curved anterior and posterior margins; flat, steeply angled lateral flanks; and (4) relatively light, circular pitting uniformly distributed across the dor- sal surface. In particular, the ornamentation and the proportions separate these taxa from other species in which the osteoderms are typically wider than they are long, flatter and often with an ovoid contour. Aspidosaurus glascocki may have partially fused osteoderms (Schoch and Milner, 2014), coarse, deeply pitted ornamentation (BMG, pers. obs.), and neural spines that contact adjacent positions (Case, 1910), features that are not found in ROM 80069. Aspidosaurus binasser, preserved with multiple osteoderm morphotypes, has been more readily compared to As. glascocki and "Aspidosaurus crucifer" than to As. chiton (Berman and Lucas, 2003), and the osteoderms most similar to the traditional Aspidosaurus-type are similar to As. glascocki and "As. crucifer." Material of Aspidosaurus sp. from the Texas red beds (Carroll, 1964) and midcontinental Carboniferous deposits (May et al., 2011) also appear more similar to other species in 
this regard than to ROMVP 80069. The holotype (and only specimen) of Aspidosaurus novomexicanus is the most complete surviving specimen of the genus, but it is poorly preserved, has not been revisited in detail since Carroll (1964) and possesses osteoderms that are distinctly wider than they are long. Osteoderms of these taxa either are not exposed in ventral profil (e.g., As. novomexicanus) or were not described in this view (e.g., As. binasser). Because ROMVP 80069 closely resembles material of Aspidosaurus, in particular the material of Aspidosaurus chiton as figured by Broili (1904), and more so than any other dissorophid, we provisionally refer the specimen to Aspidosaurus.

Subfamily DISSOROPHINAE Williston, 1910b

Referred material. ROMVP 80070, partial left humerus (Figure 12.1-2); ROMVP 80071, partial right scapulocoracoid (Figure 12.3-4); ROM 80103, complete left humerus (Figure 12.5-6).

Description and comparison. ROMVP 80071 is a partial right scapulocoracoid in which the glenoid region is preserved (Figure 12.3-4). ROMVP 80070 is a partial left humerus in which the proximal end is preserved (Figure 12.1-2). It partially preserves a blade-like ridge (the anterior humeral keel, following Pawley and Warren, 2006) extending from the deltoid crest on the proximal end down the anterior face of the shaft. ROM 80103 is a complete left humerus that is about two-thirds the length of the humerus in $\mathrm{OMNH} 73206$ a (Figure 12.5-6). The shaft is slender and relatively flattened, with an identical thin, blade-like humeral keel to that seen in ROM 80103 and OMNH 73206a. The distal and proximal ends are set at about an 80-degree angle to each other.

Identification. The referral of these specimens to the subfamily level is based on their identical morphology to a more definitively dissorophine specimen, OMNH 73206a (Gee and Reisz, 2018b). ROMVP 80071 is slightly larger than in the corresponding scapulocoracoid of that specimen. ROMVP 80070 is slightly larger than the humerus of OMNH 73522a, while ROM 80103 is markedly smaller. Gee and Reisz (2018b) previously noted that the humerus of OMNH 73522a was identical to one figured by Williston (1910a) that was noted to be a new taxon but that was never described (or identified by specimen number). The specimen (FMNH UC 1086) was located in the collections of the Field Museum by BMG and is indicated to be from "near Seymour in Baylor County." Its taxonomy is listed as unknown on the collections card. It is figured here to establish its record and morphol- ogy for future workers (Appendix 4). The size range captured between the three Richards Spur humeri provides further evidence for taxonomic distinction from known taxa (rather than ontogenetic variation).

\section{DISSOROPHUS Cope, 1895 sensu Milner, 2003}

Dissorophus cf. multicinctus Cope, 1895 sensu Schoch and Milner, 2014

Referred material. ROMVP 80072, partial, disarticulated posterior skull table and occiput in articulation with a series of osteoderms covering 13 vertebral positions (Figure 13); ROMVP 80073, partial, articulated posterior skull and occiput in articulation with a series of nine osteoderm positions and clavicle (Figure 14); ROMVP 80074, anterior shield with corresponding anteriormost internal osteoderm (Figure 15.1); ROMVP 80075, anterior shield (Figure 15.2); ROMVP 80076, internal osteoderm articulated with fragmentary internal-external pair and partial neural spines (Figure 16); ROMVP 80077, articulated series of osteoderms (minimum of three positions) with possible interclavicle (Figure 15.3-4).

Description and comparison. Cranial material of ROMVP 80072 is represented by a fragment of the posterior skull table (Figure 13). Most of the left postfrontal is preserved at the posteromedial orbital margin. The element is anteroposteriorly long and rectangular, contributing slightly more to the medial orbital margin than to the posterior margin in its present state; this morphology is most comparable to the condition seen in Broiliellus (DeMar, 1967; Holmes et al., 2013). A left parietal is complete and contains the outline of the pineal foramen, which is marked by a slightly elevated circum-pineal ridge and is found in the anterior third of the bone (Figure 13). The element is quadrilateral, being indented anterolaterally for the postfrontal. Adjacent fragments tentatively identified as part of the supratemporal are largely uninformative. The right postparietal is a transverse rectangle slightly wider than it is long but not to the degree seen in eucacopines. The right tabular is a small, short element (Figure 13). It tapers posteroventrolaterally and appears to be almost fully exposed. A fragment of the squamosal is broken off anteriorly and positioned below the supratemporal in a vertical orientation. The anterior and dorsal margins are ornamented, but the posterior margin is mostly smooth where it contributes to the supratympanic flange. The flange is slightly medially inset and separated from the ornamented portion by an elevated ridge. Cranial ornamentation does not differ greatly between the two specimens. Semi-circular 

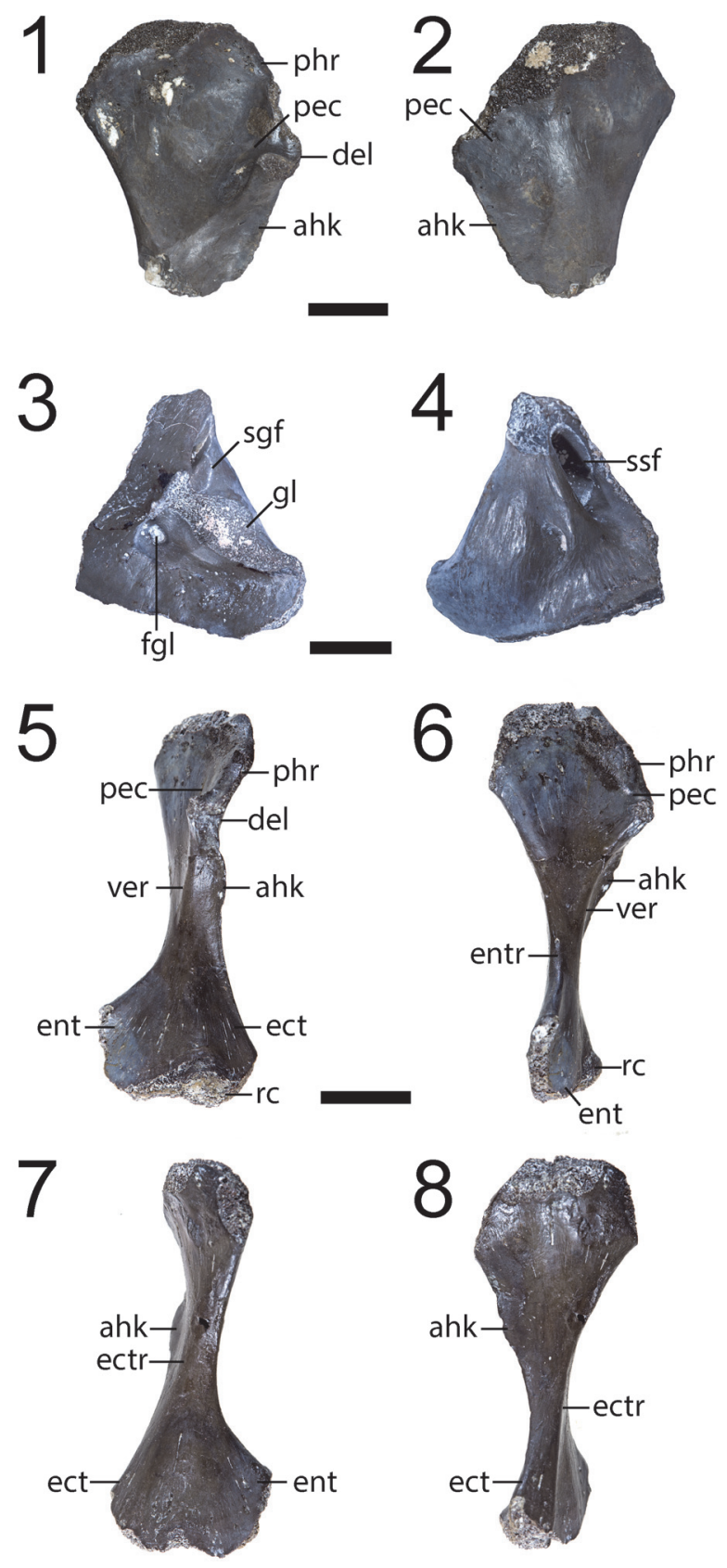

FIGURE 12. Postcrania of new referred specimens of Dissorophinae indet. 1, Photograph of ROMVP 80070 (partial humerus) in anterior profile; 2 , the same in posterior profile; 3, photograph of partial ROMVP 80071 (partial scapulocoracoid) in posterolateral profile; 4, the same in anteromedial profile; 5, photograph of ROMVP 80103 (complete humerus) in flexor profile; $\mathbf{6}$, the same in anterior profile; $\mathbf{7}$, the same in extensor profile; $\mathbf{8}$, the same in posterior profile. Scale bars equal $1 \mathrm{~cm}$.

pitting with tiny foramina characterizes most of the elements, although a pattern of ridges and grooves is present near the pineal foramen (Figure 13). The right exoccipital has been dislodged posterior to the skull table. It has the typical waisted morphology and lacks notable landmarks. Several dozen thin plates are scattered around the cranial fragments. Many of these are denticulate palatal plates, widely found in other dissorophoids, among other temnospondyls (Gee et al., 2017) and some early tetrapods (e.g., Clack et al., 2012). A set of seven, larger articulated plates are present below 
the left postfrontal (Figure 13); they likely represent sclerotic plates.

Osteoderms associated with 13 vertebral positions are preserved in articulation with the fragmentary cranium (Figure 13). The anterior-most position is a greatly enlarged "shield" typical of Dissorophus that is about four times as long anteroposteriorly as all subsequent positions. Its anterior margin is curved, and the ventral margin is unornamented, presumably for overlap by the adjacent osteoderm. Only this shield and subsequent internal osteoderms are exposed dorsally. The corresponding external osteoderms are preserved on a third block but are relatively uninformative in ventral profile other than confirming that they lack any sort of ventral flange, a feature that is found in eucacopines (e.g., Dilkes, 2009). All osteoderms are transversely broad and ornamented in a similar fashion to the cranial fragments.

Cranial material of ROMVP 80073 is represented by the right posterolateral corner of the skull roof (Figure 14). A partial maxilla is also found on top of the osteoderms of this specimen. It bears 13 teeth and 11 vacant tooth positions and probably had at least twice as many teeth when complete based on the typical presence of a long dentulous region of the maxilla in dissorophids (e.g., DeMar, 1968; Reisz et al., 2009). The teeth are straight, conical, and lack fluting. These differ from those of Cacops, which are recurved and with fluting (Reisz et al., 2009; Fröbisch and Reisz, 2012). The teeth are also smaller than comparably sized specimens of Cacops. Like ROMVP 80073, the fragmentary supratemporal is uninformative. The postparietal is rectangular, slightly wider than it is long. The posterior margin is gently elevated into a rounded nodule, also noted in Dissorophus multicinctus by DeMar (1968, p. 1214-1215). The right tabular is notably elongate in comparison to ROMVP 80072 (Figures 13, 14). It extends posterolaterally in a horizontal plane that is continuous with the rest of the skull roof before dipping steeply. A rounded nodule is also found near the posterior margin of this element. Ornamentation is similar to that of ROMVP 80072 but is slightly taller and more rugose. The maxilla is typified by grooves that elongate outward from the ventral margin (Figure 14). The right exoccipital is dislodged posterior to the tabular. It is identical to that of ROMVP 80072. A stapes is present in the otic embayment, with the distal tip facing outward in the presumed natural articulation (Figure 14). It is narrowest at the distal end and expanded slightly, both anteroposteriorly and dorsoventrally into a broader proximal end.
The shaft is slightly dorsally convex, with an oval stapedial foramen at the base. The palate and braincase appear to be entirely lost. A clavicle is partially exposed beneath a varanopid vertebral column (Figure 14). It constitutes the broad, flattened portion that would articulate with the interclavicle and is prominently striated. The anterior shield is present but tilted at a steep angle, with its anterior margin projecting dorsally and its ventral margin exposed on the underside of the block. This specimen preserves nine osteoderm positions posterior to the anterior shield. Beyond a slightly larger size and more developed ornamentation, they are identical to those of ROMVP 80072.

ROMVP 80074 and 80075 are isolated anteriormost osteoderms (Figure 15.1-2). They are identical in morphology and differ only in the development of ornamentation, which is greater in the larger specimens (ROMVP 80074, ROMVP 80073).

ROMVP 80077 is a small block with three typical trunk osteoderms (Figure 15.3-4). A partial interclavicle is preserved in ROMVP 80077 (Figure 15.4). In addition to small, irregular pitting, it also bears striations.

ROMVP 80076 is a small block with three osteoderms (one external, two internal) and five articulated vertebral positions (Figure 16). The internal osteoderms each have a bifurcated flange that is larger anteriorly (Figure 16.5). The osteoderms are slightly dislodged from the neural spine, but it is presumed that the bifurcations framed the neural spine anteriorly and posteriorly. This was figured by Demar (1968: fig. 7) for Dissorophus multicinctus in the fifth, sixth and possibly seventh vertebral positions and corresponds to the osteoderms immediately following the anteriormost shield. No flange is present on the small fragment of the external osteoderm. Each bifurcation is subtriangular in lateral profile. The neural spines are relatively short and wide, without any dorsoventral expansion or constriction. They are unossified at the tips and lack any lateral ridges or grooves reported in other dissorophids from the locality (Gee and Reisz, 2018a, 2018b). Any notch that could have accommodated the ventral flange is also absent. Six pleurocentra and four intercentra are scattered throughout the block. They have the typical morphology of rhachitomous temnospondyls. A few ribs, preserved proximally, are also present. The heads are broadly expanded and uncinate processes were at least partially developed, extending at a right angle posteriorly from the rib shaft. 


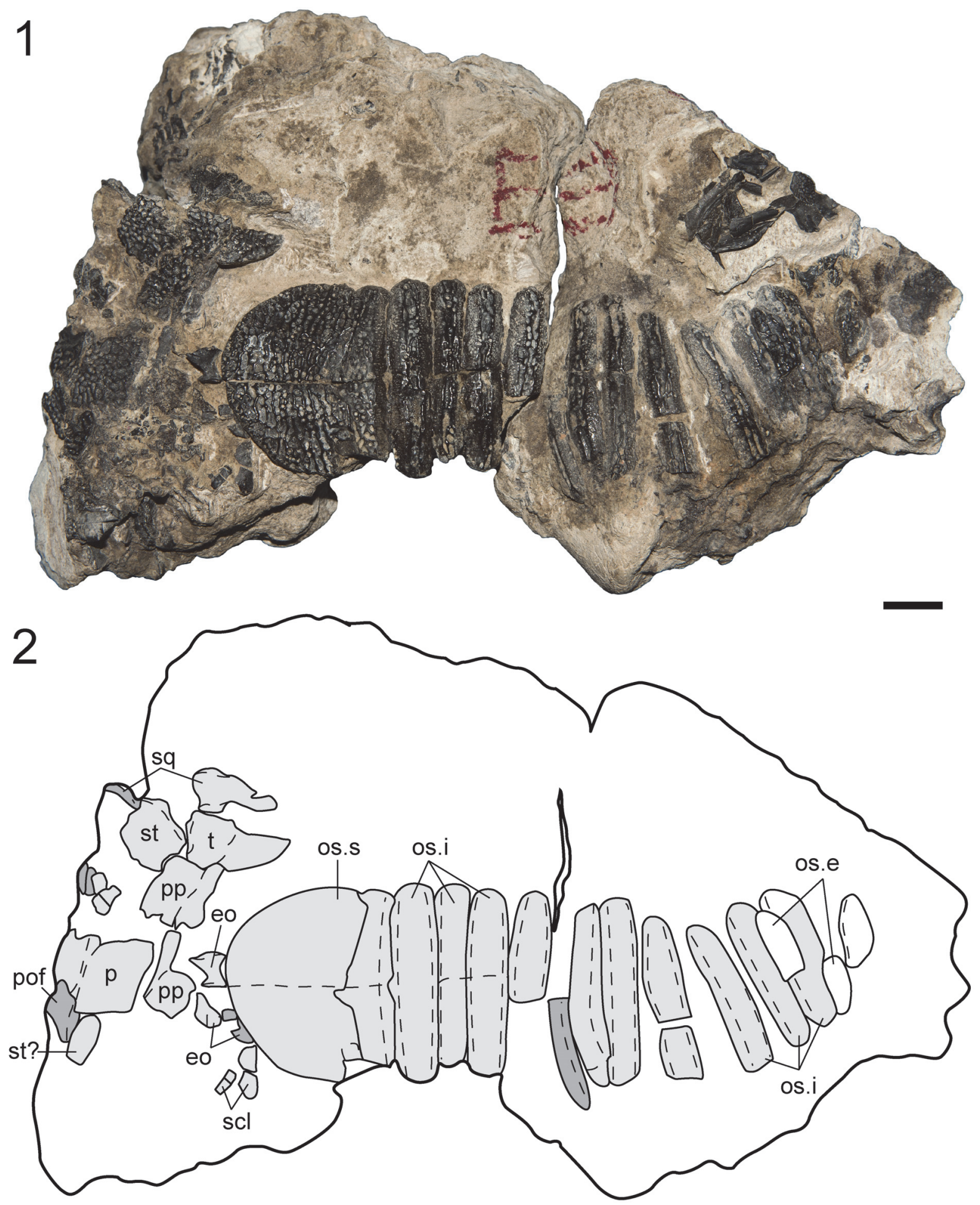

FIGURE 13. Partial skull and postcrania of new referred specimen of Dissorophus cf. multicinctus, ROMVP 80073. 1, photograph in dorsal profile; 2 , line drawing of the same. Scale bar equals $1 \mathrm{~cm}$. 


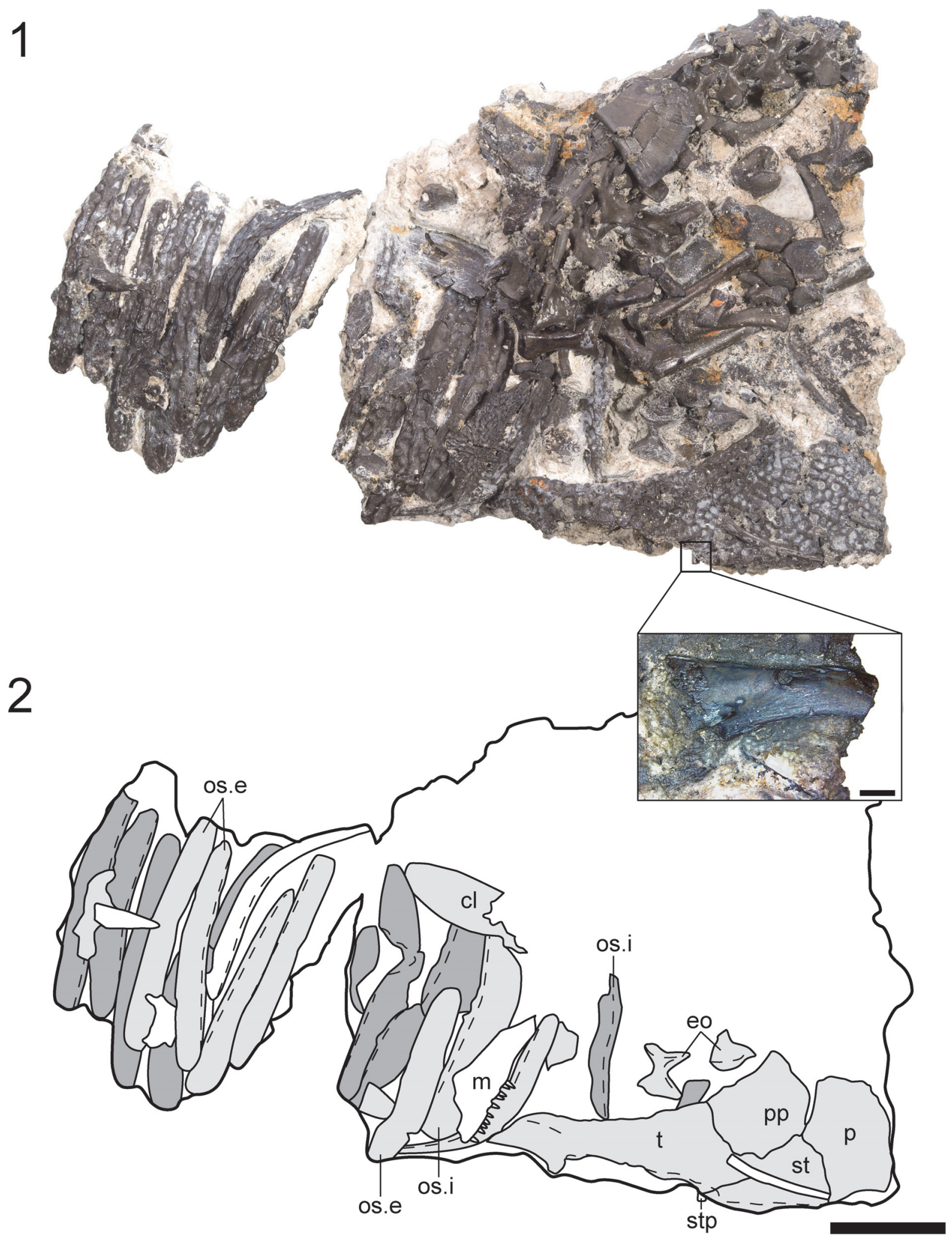

FIGURE 14. Partial skull and postcrania of new referred specimen of Dissorophus cf. multicinctus, ROMVP 80072. 1, photograph in dorsal profile; $\mathbf{2}$, line drawing of the same. Inset is a photograph of the stapes in posterior profile. Scale bar equals $1 \mathrm{~cm}$ for the main figure and $2 \mathrm{~mm}$ for the inset. 

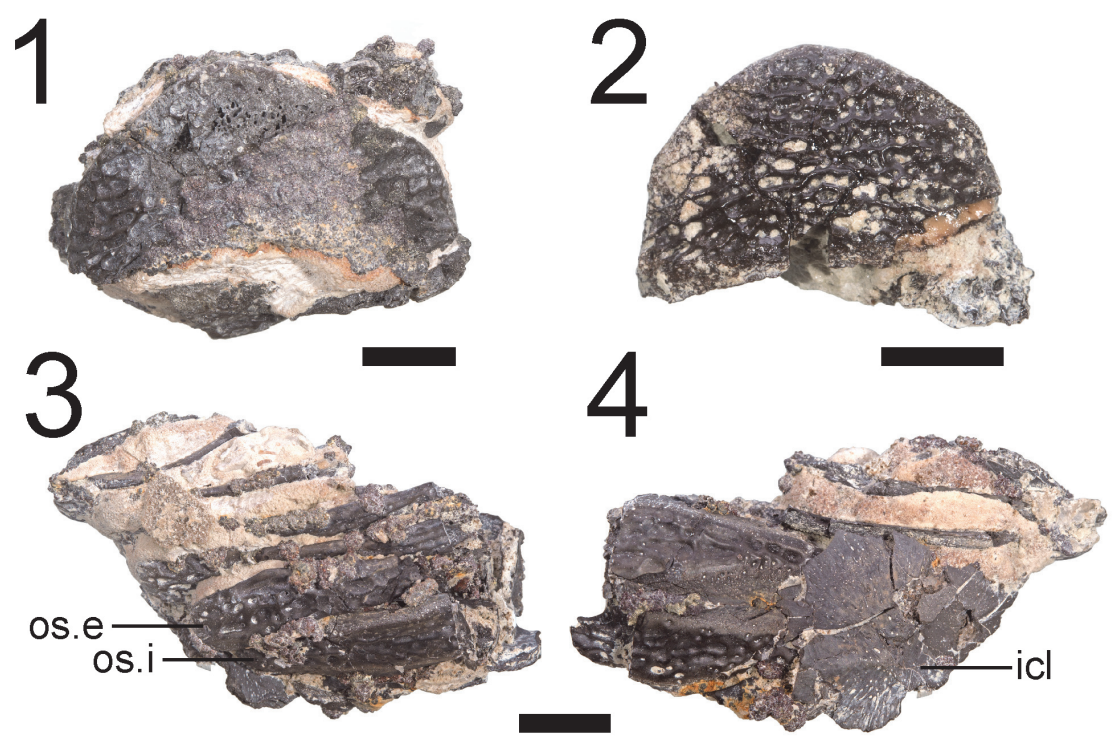

FIGURE 15. Photographs of new referred specimens of Dissorophus cf. multicinctus. 1, ROMVP 80074 in dorsal profile; 2, ROMVP 80075 in dorsal profile; 3, ROMVP 80077 in dorsal profile; 4, the same in ventral profile. Scale bars equal $1 \mathrm{~cm}$.

Identification. The postcranial material is the most informative and allows for ROMVP 80072, ROMVP 80073 , ROMVP 80074 and ROMVP 80075 to be referred on the basis of the greatly enlarged anteriormost osteoderm (the "shield") (Figures 13, 14, 15). The cranial material of ROMVP 80072 and ROMVP 80073 is less informative (Figures 13, 14), but a few features support non-Cacops affinities (Cacops being the best-known dissorophid from Richards Spur). The posterior cranial elements are proportionately longer than in the abbreviated posterior skull table of eucacopines. The ornamentation consists of more evenly developed circular pitting, rather than developed tubercles (Cacops morrisi) or ridges (Cacops woehri) (Figures 13, 14). The maxillary dentition of ROMVP 80073 is substantially smaller and non-recurved; the marginal dentition of Cacops is larger and fewer in number than most dissorophids (Gee and Reisz, 2018a). Almost 20 positions are identified in a fragment that probably represents no more than a third of the entire dentulous length, compared to full maxillary tooth counts in the 27-35 range for the Richards Spur Cacops (Gee and Reisz, 2018a). The extensive transverse width of the osteoderms of ROMVP 80072 and ROMVP 80073 (Figures 13, 14) also support Dissorophus affinities. By relation, ROMVP 80076 and ROMVP 80077, which are transversely broad and similarly ornamented (Figures 15, 16), can also be referred to Dissorophus. Some species of Broiliellus (B. texensis, B. arroyoensis) have broader osteoderms that approach but do not equal the relative width in Dissorophus, and these two species apparently have only a single series of osteoderms (DeMar, 1966). The osteoderms of Broiliellus brevis and Broiliellus reiszi (the only species of Broiliellus with a double series) are comparable to those of Cacops in their width (Carroll, 1964; Holmes et al., 2013). Broiliellus reiszi also apparently lacks ventral flanges on the internal series (Holmes et al., 2013). The specimen examined here through computed tomography (ROMVP 80076, Figure 16) preserves bifurcated ventral flanges that are similar to those illustrated for the anteriormost trunk region of Dissorophus multicinctus by DeMar (1968).

Dissorophus is presently monospecific $(D$. multicinctus), but all of the Richards Spur dissorophoids are endemic to the locality at the species level except for Pasawioops mayi, so the material described here could belong to a new species. However, this interpretation is mostly informed speculation; there are no apparent differences from D. multicinctus among the six specimens from Richards Spur referred to Dissorophus. The morphology of the neural spines (short and broad, without lateral ridges) in ROMVP 80076 also indicates that this material does not belong to the same taxon as the indeterminate dissorophine described by Gee and Reisz (2018b). Although this material is the first confident documentation of Dissorophus from Richards Spur, Bolt reported indeterminate osteoderm fragments from the locality, at 

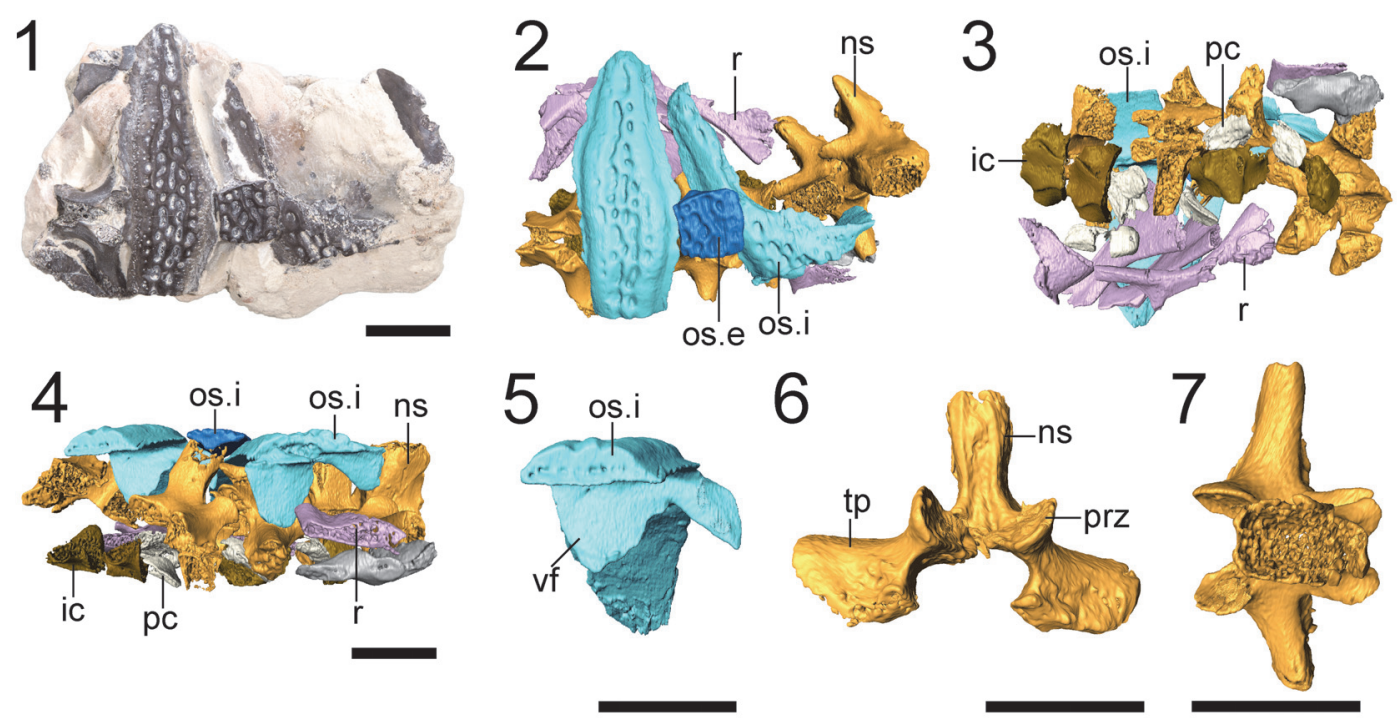

FIGURE 16. Postcrania of new referred specimen of Dissorophus cf. multicinctus, ROMVP 80076. 1, photograph in dorsal profile; 2, segmented rendering in dorsal profile; 3, segmented rendering in ventral profile; 4, segmented rendering in left lateral profile; $\mathbf{5}$, isolated external osteoderm in left ventrolateral profile showing bifurcated ventral flange. 6, isolated neural arch and spine in anterior profile; 7 , the same in dorsal profile. Scale bars equal $1 \mathrm{~cm}$.

least one of which (Bolt, 1974a, figure 3B) may also belong to this taxon (FMNH UR 2404).

\section{DISCUSSION}

\section{New Insights into Dissorophid Osteoderms}

The CT analysis of several osteoderm morphotypes contributes new information regarding the internal morphology and ontogeny of osteoderms in dissorophids, with correspondent insights into dissorophid taxonomy. ROMVP 80076, referred to Dissorophus cf. D. multicinctus, preserves a bifurcated ventral flange of the internal series. This feature was previously reported in anterior trunk positions of $D$. multicinctus by DeMar (1968, figure 7) and provides the most compelling evidence for the referral of transversely wide osteoderms from Richards Spur to the genus in the absence of the enlarged anterior shield found in some of the other specimens described here.

ROMVP 80078, referred to Cacops sp., is identical to those previously reported for the taxon. The noteworthy feature described here is the presence of a ventral flange of the internal osteoderm that inserts into an enclosed groove at the tip of the neural spine (Figure 2). Fusion of the neural spine to the internal osteoderm, as seen in this specimen, has long been noted in Cacops (e.g., DeMar, 1966). However, previous work (e.g., Williston, 1910a; DeMar, 1966) did not indicate the presence of ventral flanges in either the internal or the exter- nal series. Bolt (1974:fig. 2) reported at least one external osteoderm from Richards Spur (FMNH UR 2402) that probably belongs to Cacops and that has a ventral flange, but he did not refer the specimen to the taxon given the paucity of dissorophid material known from the locality at the time. Thus, it was not until the detailed study of Dilkes and Brown (2007) that the presence of small but stout ventral flanges on the external series that inserts between adjacent internal osteoderms was fully recognized in Cacops. These become even more ventrally extensive to insert between the neural spines during later stages of ontogeny (Dilkes and Brown, 2007; Dilkes, 2009). The CT analysis of ROMVP 80078 revealed a similarly stout ventral flange of the internal osteoderm that inserts into a groove at the tip of the neural spine. Presumably, its ossification and development were linked to that of the fusion between the neural spine and the osteoderm, although it remains unclear whether complete fusion was accomplished (the sutural demarcation still being distinct in large specimens [Dilkes and Brown, 2007]). If so, that would suggest that the flange would either be absent or relatively undeveloped in the smaller internal osteoderms of immature individuals. As a result, although these osteoderms are more likely to separate from the neural spine and to be exposed ventrally during preservation, identification of this flange may not be possible if it is not present in the first place. The tight contact in larger specimens 
would probably limit the potential for a clean postmortem disarticulation, and the flange would not be detectable in articulated larger specimens without either histological or tomographic analysis.

ROMVP 80069, provisionally referred to Aspidosaurus, is the most complex specimen. There are four mutually exclusive hypotheses regarding its taxonomic affinities that we consider here: 1) this specimen belongs to a distinct and novel taxon characterized by a double series of Aspidosaurustype osteoderms; 2) this specimen belongs to an existing species of a non-monophyletic Aspidosaurus, only some taxa which have a double osteoderm series; 3) this morphology represents a presently unrecognized part of a known dissorophid with similar osteoderms to Aspidosaurus (e.g., Scapanops neglectus); and 4), as is suggested here by our referral, this specimen belongs to a monophyletic Aspidosaurus as historically recognized, indicating that a largely hidden double series characterizes the genus. Our interpretation is predicated primarily on the apparent similarity of ROMVP 80069 to the illustrations of the genotype, Aspidosaurus chiton, by Broili (1904).

However, this identification cannot be anything but provisional for a number of reasons. Firstly, all currently recognized species of Aspidosaurus are represented only by their holotypes, so while a sizeable amount of material exists in collections as Aspidosaurus sp., affinities to either the genus or to a particular species are somewhat tenuous. Secondly, this paucity of properly referable material includes the loss of Aspidosaurus chiton during an air raid on Munich during World War II in 1944. Because this is the name-bearing specimen for the genus, it is, in a way, technically impossible to ever determine with confidence whether ROMVP 80069 or any other specimen properly belongs to Aspidosaurus. Reevaluation of existing specimens could produce important data to test this hypothesis. However, even if other material currently assigned to Aspidosaurus revealed the same hidden internal osteoderm, such material's placement could be challenged along the same lines as ROMVP 80069. A third challenge is the quality of preservation. The Richards Spur material is well-known for being exceptionally well preserved, which permits both high-quality CT scans and observation of details externally. Small exposures of the internal osteoderm in non-ventral views are identifiable for ROMVP 80069 because of this preservational quality, but most material from the Texas red beds (from which most Aspidosaurus material was collected) is not of a similar quality. We did not immediately recognize the presence of a distinct internal series until it was confirmed through the CT analysis. The quality of preservation, or lack thereof, may have led to an overlooking of the internal series in other specimens of Aspidosaurus since the internal osteoderms are smaller than the external ones, largely unornamented, and mostly covered when articulated. The apparent lack of attention to the ventral surfaces, in which the internal osteoderm is more apparent, as reflected in the literature is another complication. The final consideration is a poor understanding of variation along the axial column and throughout ontogeny in the osteoderms of most dissorophids. Variation could evidently be quite pronounced along the axial column as evidenced by the three distinct osteoderm morphotypes of Aspidosaurus binasser (Berman and Lucas, 2003), although it is far less pronounced in Cacops aspidephorus and Dissorophus multicinctus (e.g., Williston, 1910a, 1910b; DeMar, 1966; Dilkes, 2009). Ontogenetic series for most dissorophids are virtually nonexistent, let alone for series of particular osteoderms or axial regions.

These findings do not overturn or shift our current understanding of dissorophid phylogeny osteoderm characters are limited in number and exert an apparently minimal influence on the tree topology (Schoch, 2012). However, our findings underscore a few major points for future consideration. Firstly, Aspidosaurus is in need of serious revision, but this undertaking is hindered substantially by the loss of the genotype. A thorough revision will probably require methods beyond simple reexamination of external morphologies (e.g., histology, CT) and a wholesale review, rather than piecemeal reappraisals. Secondly, additional work will be needed to more fully assess the evolutionary trajectories that produced the widely varied osteoderms within dissorophids and to better characterize the vertebra-osteoderm relationship. For example, the insertion of a ventral flange of the internal osteoderm into a groove on the neural spine was thought to only occur in some vertebrae of Dissorophus but is here demonstrated to also occur in large individuals of Cacops. The only detailed reviews of dissorophid osteoderms (e.g., DeMar, 1966) are now largely outdated following substantial work and revision in the past few decades. Histology offers great potential for improved understanding of the vertebra-osteoderm interface and the development of the osteoderms (e.g., the nature of the anterior shield in Dissorophus), but there has been limited histological 
work to date (e.g., Witzmann and Soler-Gijón, 2010).

\section{Dissorophid Evolution and Diversity}

The presence of Dissorophus and cf. Aspidosaurus further expands the already taxonomically diverse dissorophoid assemblage at Richards Spur to seven distinct taxa (three amphibamiforms [three genera, three species], four dissorophids [three genera, four species], one trematopid). Regardless of whether ROMVP 80069 belongs to Aspidosaurus or to an Aspidosaurus-like dissorophid, the specimen can be distinguished from all other dissorophoid genera at the locality. The indeterminate dissorophine (OMNH 73522a) without osteoderms or cranial material that was described by Gee and Reisz (2018b) represents an eighth taxon, as it remains distinct from other taxa following this description of new material.

The documentation of Dissorophus and cf. Aspidosaurus furthers the taxic overlap between the diverse Richards Spur locality and the classic Texas red beds. Of the dissorophoid genera at Richards Spur, only one is not found in the Texas red beds (Doleserpeton [Bolt, 1969]). Conversely, among these seven genera, only one species is found in both environments (Pasawioops mayi [Maddin et al., 2013]). The indeterminate dissorophine from Richards Spur and the isolated humerus from the Texas red beds (FMNH UC 1086) that Williston (1910) noted may belong to the same taxon, but additional material is needed to assess this given the apparent conservatism in dissorophid postcrania (Gee and Reisz, 2018b). This pattern is quite distinct from the major amniote clades found at Richards Spur. For example, there are six genera and eight species of parareptiles at the locality. Only one of these genera (Bolosaurus) occurs in the Texas red beds, and the Richards Spur species (B. grandis) is endemic to the site (e.g., MacDougall et al., 2016). A similar pattern is present for captorhinid eureptiles (five genera, five species, one indeterminate form), for which Captorhinus aguti is the only taxon that also occurs in the Texas red beds (e.g., Modesto et al., 2018). The less speciose synapsids (five genera, five species) are known from more fragmentary specimens and have not been as extensively studied (precluding confident species-level assignment), but Mycterosaurus, Dimetrodon, and Varanops occur in both environments, while the two caseids (Oromcyter, Arisierpeton) are endemic to Richards Spur (Reisz et al., 1997; Maddin et al., 2006; Brink et al., 2019; Reisz, 2019). Non-dissorophoid non-amni- otes are otherwise rare at Richards Spur. The aisstopod Sillerpeton permanium is found only at Richards Spur. 'Microsaurs,' (four genera, four species) are a clade whose affinities within the tetrapod crown remain controversial, ranging from placement within the amniote crown-group as sauropsid reptiles (e.g., Pardo et al., 2017) to a position as non-amniotes on the lissamphibian stem (e.g., Marjanović and Laurin, 2013). This clade exhibits a mixed pattern of faunal overlap. Cardiocephalus occurs in the Texas red beds (Broili, 1904), but Cardiocephalus peabodyi is found only at Richards Spur (Carroll and Gaskill, 1978). The genus Euryodus occurs in the Texas red beds, but the Richards Spur taxon (Euryodus dalyae) is otherwise only found at the South Grandfield locality in Oklahoma (Daly, 1973).

This disparity between dissorophoids (the vast majority of non-amniotes, both taxonomically and by relative abundance) and amniotes may be proposed to be the product of the inherent subjectivity of taxonomic distinction and division at higher taxonomic levels (i.e., excessive splitting of amniotes or excessive lumping of non-amniotes). However, this disparity may also be reasonably proposed to be the result of fundamental differences between non-amniotes and amniotes. It is generally well-accepted that changes to the global landscape and climate in the late Paleozoic favored the overall radiation and dispersal of amniotes compared to non-amniotes, especially in terrestrial environments (e.g., Brocklehurst et al., 2018; Dunne et al., 2018). Among temnospondyls, dissorophoids have an unusually diverse subset of taxa that radiated in terrestrial ecosystems alongside Permo-Carboniferous amniotes (e.g., Pardo et al., 2019), reaching peak diversity in the early Permian. However, after the early Permian, trematopids are totally absent, dissorophids are represented almost entirely by a handful of late Permian taxa from Eurasia (Gubin, 1980; Witzmann, 2005; Liu, 2018), and amphibamiforms are represented only by the relict form Micropholis from the Early Triassic of South Africa (notwithstanding the branching of lissamphibians from amphibamiforms). Because temnospondyls (as non-amniotes) are traditionally interpreted to be more physiologically dependent on water compared to amniotes, they may have been confined to radiations within particular niches and morphologies that they thrived in, resulting in greater taxonomic homogeneity across geographic regions during the early Permian. This hypothesis is in agreement with a proposed greater dispersal capa- 
bility of amniotes due to their reduced physiological constraints (e.g., Brocklehurst et al., 2018; Dunne et al., 2018). Greater ecological expansion of amniotes (e.g., into herbivory) probably also influences observed patterns of early Permian communities. In short, the terrestrial dissorophoids could have simultaneously been successful in the sense of persisting across terrestrial landscapes (stability) while still being restricted in overall evolutionary radiation compared to amniotes. Substantial dissorophoid declines after the early Permian compared to amniote groups like eureptiles and synapsids could thus reflect the loss of those narrow niches in which dissorophoids thrived during the early Permian.

At a smaller local scale, the relative abundance of the various dissorophids at Richards Spur also merits some discussion. To date, ROMVP 80069 represents the only material tentatively referable to Aspidosaurus. This scarcity is not unlike its general paucity in other Permo-Carboniferous localities in which it is largely recognized by osteoderms, as at Richards Spur. Cranial material of Dissorophus beyond the fragments noted here is unknown, but isolated osteoderms of the same morphology to those described here are frequently identified in aggregations of surface-collected material. Conversely, material of Cacops is much more abundant. Six essentially complete skulls of Cacops morrisi have been described (Reisz et al., 2009; Gee and Reisz, 2018a; this study), and an additional small skull (SMNS 91418) was referred to the taxon by Schoch (2012). Cacops woehri is known from five partial skulls, two of which are essentially informationally complete by virtue of being broken down the midline (Fröbisch and Reisz, 2012; Fröbisch et al., 2015; this study). OMNH 79340 probably pertains to one of the species of Cacops, and various postcranial elements (e.g., osteoderms) that are sometimes referred to Cacops sp. are also common. The same pattern is apparent in relative abundance studies (MacDougall, 2017). Size-related taphonomic sorting and ecology are unlikely explanators given that most early Permian dissorophids were comparably moderately sized faunivorous tetrapods. The nature of collection (via serendipitous exposure and exhumation of materials during the active quarrying of limestone) may explain some aspects of our knowledge of the locality (e.g., greater representation of well-preserved skulls than isolated postcrania), but this aspect seems rather improbable as an explanator of relative abundance between taxa. Whether the observed pattern reflects the true relative abun- dance of the Richards Spur paleoenvironment will require additional testing and work at similar localities (e.g., the nearby Bally Mountain locality) where greater control can be exerted over the entire sample to mitigate collection biases and to examine spatial relationships within karst systems. Ongoing studies of the depositional setting and mechanisms associated with fissure fill deposits in this region are an important component for a better understanding of Richards Spur. Most of the dissorophoid diversity at Richards Spur was only recognized following exposure and collection of an unusually fossiliferous pocket in 2005 that produced virtually all of the material of the trematopid Acheloma dunni, the amphibamiform Pasawioops mayi, the dissorophids Cacops morrisi, Cacops woehri, and all of the specimens described here. This pocket includes some of the best-preserved and most complete material from the locality of both amniotes (e.g., Reisz et al., 2014) and nonamniotes (e.g., Gee and Reisz, 2018a). The historic sample of dissorophoids otherwise consisted of cranial and postcranial material of Doleserpeton (Bolt, 1969), olsoniform limbs (Sullivan et al., 2000), fragmentary dissorophid osteoderms (Bolt, 1974a), isolated Cacops elements (mostly quadrates) (Bolt, 1977) and a partial trematopid skull table (Bolt, 1974b). At present, the active quarrying operation precludes any study of the relationship of different fissure fills from which tetrapods have been collected over the course of the last century, and the precise mechanisms by which pocket accumulations formed in this setting remain unknown.

\section{ACKNOWLEDGMENTS}

Thanks to J. Larsen (OMNH) and K. Seymour (ROMVP) for assistance with collections numbers. Thanks to W. Simpson and A. Stroup (FMNH) for facilitating a collection visit by BMG that led to the unexpected rediscovery of Williston's mystery humerus. Thanks to D. Scott for photographs, to N. Horsman and L. Candela for specimen illustrations, and to T. Brys, B. Dunn, M. Feese, R. Kaiser, and $W$. May for their collection and generous donation of some of the specimens reported here. Thanks to the two reviewers and the editor for constructive feedback that improved this manuscript. This research was supported by an NSERC Discovery Grant to RRR, an Ontario Graduate Scholarship (OGS) grant to BMG, and the University of Toronto. 


\section{REFERENCES}

Anderson, J.S. 2005. On the skull of Cacops aspidephorus Williston (Tetrapoda: Temnospondyli: Dissorophidae) from the Lower Permian of Texas. Part 1: lower jaw anatomy. New Mexico Museum of Natural History and Science Bulletin, 30:15.

Anderson, J.S., Henrici, A.C., Sumida, S.S., Martens, T., and Berman, D.S. 2008a. Georgenthalia clavinasica, a new genus and species of dissorophoid temnospondyl from the Early Permian of Germany, and the relationships of the family Amphibamidae. Journal of Vertebrate Paleontology, 28(1):61-75. https://doi.org/10.1671/02724634(2008)28[61:GCANGA]2.0.CO;2

Anderson, J.S., Reisz, R.R., Scott, D., Fröbisch, N.B., and S. S. Sumida. 2008b. A stem batrachian from the Early Permian of Texas and the origin of frogs and salamanders. Nature, 453:515-518. https://doi.org/10.1038/nature06865

Berman, D.S. and Lucas, S.G. 2003. Aspidosaurus binasser (Amphibia, Temnospondyli), a new species of Dissorophidae from the Lower Permian of Texas. Annals of Carnegie Museum, 72(4):241-262.

Bolt, J.R. 1969. Lissamphibian origins: possible protolissamphibian from the Lower Permian of Oklahoma. Science, 166(3907):888-891. https://doi.org/10.1126/science.166.3907.888

Bolt, J.R. 1974a. Armor of dissorophids (Amphibia: Labyrinthodontia): an examination of its taxonomic use and report of a new occurrence. Journal of Paleontology, 48(1):135-142.

Bolt, J.R. 1974b. A trematopsid skull from the Lower Permian, and analysis of some characters of the dissorophoid (Amphibia, Labyrinthodontia) otic notch. Fieldiana Geology, 30(3):67-79.

Bolt, J.R. 1977. Cacops (Amphibia: Labyrinthodontia) from the Fort Sill locality, Lower Permian of Oklahoma. Fieldiana Geology, 37(3):61-73.

Boulenger, G.A. 1902. Amphibia, p 381-384. In Chisholm, H., Wallace, D.M., Hadley, A.T., and Hooper, F.H. (eds.), Vol. I, Encyclopaedia Britannica, 10th ed. London: Adam and Charles Black.

Brink, K.S., MacDougall, M.J., and Reisz, R.R. 2019. Dimetrodon (Synapsida: Sphenacodontidae) from the cave system at Richards Spur, OK, USA, and a comparison of Early Permian-aged vertebrate paleoassemblages. The Science of Nature, 106(1-2):2. https://doi.org/10.1007/s00114-018-1598-1

Brocklehurst, N., Dunne, E.M., Cashmore, D.D., and Fröbisch, J. 2018. Physical and environmental drivers of Paleozoic tetrapod dispersal across Pangaea. Nature Communications, 9(1):5216. https://doi.org/10.1038/s41467-018-07623-x

Broili, F. 1904. Permische Stegocephalen und Reptilien aus Texas. Palaeontographica, 51:1120.

Carroll, R.L. 1964. Early evolution of the dissorophid amphibians. Bulletin of the Museum of Comparative Zoology, 131:163-250.

Carroll, R.L. and Gaskill, P. 1978. The Order Microsauria. Memoirs of the American Philosophical Society, 126:1-211.

Case, E.C. 1910. New or little known reptiles and amphibians from the Permian (?) of Texas. Bulletin of the American Museum of Natural History, 28:163-181.

Clack, J.A., Witzmann, F., Müller, J., and Snyder, D. 2012. A colosteid-like early tetrapod from the St. Louis Limestone (Early Carboniferous, Meramecian), St. Louis, Missouri, USA. Fieldiana Life and Earth Sciences, (89(2):17-40. https://doi.org/10.3158/2158-55205.1.17

Cope, E.D. 1895. A batrachian armadillo. American Naturalist, 29:998.

Daly, E. 1973. A Lower Permian vertebrate fauna from southern Oklahoma. Journal of Paleontology, 47(3):562-589.

DeMar, R.E. 1966. The phylogenetic and functional implications of the armor of the Dissorophidae. Fieldiana Geology, 16(3):55-88.

DeMar, R.E. 1967. Two new species of Broiliellus (Amphibians) from the Permian of Texas. Fieldiana Geology, 16(5):117-129.

DeMar, R.E. 1968. The Permian labyrinthodont amphibian Dissorophus multicinctus, and adaptations and phylogeny of the family Dissorophidae. Journal of Paleontology, 42(5):12101242. 
Dilkes, D.W. 2009. Comparison and biomechanical interpretations of the vertebrae and osteoderms of Cacops aspidephorus and Dissorophus multicinctus (Temnospondyli, Dissorophidae). Journal of Vertebrate Paleontology, 29(4):1013-1021. https://doi.org/ 10.1671/039.029.0410

Dilkes, D. and Brown, L.E. 2007. Biomechanics of the vertebrae and associated osteoderms of the Early Permian amphibian Cacops aspidephorus. Journal of Zoology, 271(4):396-407. https://doi.org/10.1111/j.1469-7998.2006.00221.x

Dunne, E.M., Close, R.A., Button, D.J., Brocklehurst, N., Cashmore, D.D., Lloyd, G.T, and Butler, R.J. 2018. Diversity change during the rise of tetrapods and the impact of the 'Carboniferous rainforest collapse.' Proceedings of the Royal Society B Biological Sciences, 285(1872):20172730. https://doi.org/10.1098/rspb.2017.2730

Fröbisch, N.B., Brar, A., and Reisz, R.R. 2015. New specimen of Cacops woehri indicates differences in the ontogenetic trajectories among cacopine dissorophids. Fossil Record, 18:73-80. https://doi.org/10.5194/fr-18-73-2015

Fröbisch, N.B. and Reisz, R.R. 2012. A new species of dissorophid (Cacops woehri) from the Lower Permian Dolese quarry, near Richards Spur, Oklahoma. Journal of Vertebrate Paleontology, 32:35-44. https://doi.org/10.1080/02724634.2012.633586

Garbe, U., Randall, T., Hughes, C., Davidson, G., Pangelis, S., and Kennedy, S.J. 2015 A new neutron radiography / tomography / imaging station DINGO at OPAL. Physics Procedia, 69:27-32. https://doi.org/10.1016/j.phpro.2015.07.003

Gee, B.M. 2018. Reappraisal of the early Permian dissorophid Alegeinosaurus from Texas, USA. Palaöntologische Zeitschrift, 92(4):661-669. https://doi.org/10.1007/s12542-018-0421-9

Gee, B.M., Haridy, Y., and Reisz, R.R. 2017. Histological characterization of denticulate palatal plates in an Early Permian dissorophoid. PeerJ, 5:e3727. https://doi.org/10.7717/peerj.3727

Gee, B.M. and Reisz, R.R. 2018a. Cranial and postcranial anatomy of Cacops morrisi, a eucacopine dissorophid from the early Permian. Journal of Vertebrate Paleontology, 38(2):e1433186. https://doi.org/10.1080/02724634.2018.1433186

Gee, B.M. and Reisz, R.R. 2018b. Postcrania of large dissorophids from Richards Spur, Oklahoma. Fossil Record, 21(1):79-91. https://doi.org/10.5194/fr-21-79-2018

Gubin, Y.M. 1980. (New Permian dissorophids of the Ural forelands.) Paleontologicheskii Zhurnal 1980(3):82-90. (In Russian)

Holmes, R., Berman, D.S., and Anderson, J.S. 2013. A new dissorophid (Temnospondyli, Dissorophoidea) from the Early Permian of New Mexico (United States). Comptes Rendus Palevol, 12(7-8):419-435. https://doi.org/10.1016/j.crpv.2013.07.002

Liu, J. 2018. Osteology of the large dissorophid temnospondyl Anakamacops petrolicus from the Guadalupian Dashankou Fauna of China. Journal of Vertebrate Paleontology 38(5):e1513407. https://doi.org/10.1080/02724634.2018.1513407.

MacDougall, M.J. 2017. Palaeoecology and Taphonomy of the Early Permian Cave System Near Richards Spur, Oklahoma, and Its Parareptilian Fauna. Unpublished Ph.D. dissertation, University of Toronto, Toronto, Ontario, Canada.

MacDougall, M.J., Modesto, S.P., and Reisz, R.R. 2016. A new reptile from the Richards Spur Locality, Oklahoma, USA, and patterns of Early Permian parareptile diversification. Journal of Vertebrate Paleontology, 36(5):e1179641. https://doi.org/10.1080/02724634.2016.1179641

MacDougall, M.J., Tabor, N.J., Woodhead, J., Daoust, A.R., and Reisz, R.R. 2017. The unique preservational environment of the Early Permian (Cisuralian) fossiliferous cave deposits of the Richards Spur locality, Oklahoma. Palaeogeography, Palaeoclimatology, Palaeoecology 475:1-11. https://doi.org/10.1016/j.palaeo.2017.02.019

Maddin, H.C., Evans, D.C., and Reisz, R.R. 2006. An Early Permian varanodontine varanopid (Synapsida: Eupelycosauria) from the Richards Spur locality, Oklahoma. Journal of Vertebrate Paleontology, 26(4):957-966. https://doi.org/10.1671/02724634(2006)26[957:AEPVVS]2.0.CO;2

Maddin, H.C., Fröbisch, N.B., Evans, D.C., and Milner, A.R. 2013. Reappraisal of the Early Permian amphibamid Tersomius texensis and some referred material. Comptes Rendus Palevol, 12(7-8):447-461. https://doi.org/10.1016/j.crpv.2013.06.007

Marjanović, D. and Laurin, M. 2013. The origin (s) of extant amphibians: a review with emphasis on the "lepospondyl hypothesis". Geodiversitas, 35(1):207-273. https://doi.org/10.5252/ g2013n1a8 
May, W., Huttenlocker, A.K., Pardo, J.D., Benca, J., and Small, B.J. 2011. New Upper Pennsylvanian armored dissorophid records (Temnospondyli, Dissorophoidea) from the US midcontinent and the stratigraphic distributions of dissorophids. Journal of Vertebrate Paleontology, 31(4):907-912. https://doi.org/10.1080/02724634.2011.582532

Milner, A.R. 2003. Longiscitula houghae DeMar, 1966 (Amphibia: Temnospondyli), a junior synonym of Dissorophus multicinctus Cope, 1895. Journal of Vertebrate Paleontology, 23(4):941-944. https://doi.org/10.1671/18

Modesto, S.P., Scott, D., and Reisz, R.R. 2018. A new small captorhinid reptile from the lower Permian of Oklahoma and resource partitioning among small captorhinids in the Richards Spur fauna. Papers in Palaeontology, 4(2):293-307. https://doi.org/10.1002/spp2.1109

Pardo, J.D., Small, B.J., and Huttenlocker, A.K. 2017. Stem caecilian from the Triassic of Colorado sheds light on the origins of Lissamphibia. Proceedings of the National Academy of Sciences, 114(27):E5389-E5395. https://doi.org/10.1073/pnas.1706752114

Pardo, J.D., Szostakiwskyj, M., Ahlberg, P.E., and Anderson, J.S. 2017. Hidden morphological diversity among early tetrapods. Nature, 546(7660):642-645. https://doi.org/10.1038/ nature22966

Pardo, J.D., Small, B.J., Milner, A.R., and Huttenlocker, A.K. 2019. Carboniferous-Permian climate change constrained early land vertebrate radiations. Nature Ecology and Evolution, 3:200-206. https://doi.org/10.1038/s41559-018-0776-z

Pawley, K. and Warren, A. 2006. The appendicular skeleton of Eryops megacephalus Cope, 1877 (Temnospondyli: Eryopoidea) from the Lower Permian of North America. Journal of Paleontology, 80(3):561-580. https://doi.org/10.1666/00223360(2006)80[561:TASOEM]2.0.CO;2

Polley, B.P. and Reisz, R.R. 2011. A new Lower Permian trematopid (Temnospondyli: Dissorophoidea) from Richards Spur, Oklahoma. Zoological Journal of the Linnean Society, 161(4):789-815. https://doi.org/10.1111/j.1096-3642.2010.00668.x

Reisz, R.R. 2019. A small caseid synapsid, Arisierpeton simplex gen. et sp. nov., from the early Permian of Oklahoma, with a discussion of synapsid diversity at the classic Richards Spur locality. PeerJ 7:e6615. https://doi.org/10.7717/peerj.6615

Reisz, R.R., MacDougall, M.J., and Modesto, S.P. 2014. A new species of the parareptile genus Delorhynchus, based on articulated skeletal remains from Richards Spur, Lower Permian of Oklahoma. Journal of Vertebrate Paleontology, 34(5):1033-1043. https://doi.org/10.1080/ 02724634.2013.829844

Reisz, R. R., Schoch, R.R., and Anderson, J.S. 2009. The armoured dissorophid Cacops from the Early Permian of Oklahoma and the exploitation of the terrestrial realm by amphibians. Naturwissenschaften, 96:789-796. https://doi.org/10.1007/s00114-009-0533-x

Reisz, R.R., Wilson, H., and Scott, D. 1997. Varanopseid synapsid skeletal elements from Richards Spur, a Lower Permian fissure fill located near Fort Sill, Oklahoma. Oklahoma Geology Notes, 57:160-170.

Schoch, R.R. 2012. Character distribution and phylogeny of the dissorophid temnospondyls. Fossil Record, 15(2):121-137. https://doi.org/10.1002/mmng.201200010

Schoch, R.R. 2019. The putative lissamphibian stem-group: phylogeny and evolution of the dissorophoid temnospondyls. Journal of Paleontology, 93(1):137-156. https://doi.org/ 10.1017/jpa.2018.67

Schoch, R.R. and Milner, A.R. 2014. Temnospondyli I, p. 1-150. In Sues, H.-D. (ed.), Handbook of Paleoherpetology, Part 3A2. Verlag Dr. Friedrich Pfeil, München.

Sigurdsen, T. and Bolt, J.R. 2010. The Lower Permian amphibamid Doleserpeton

(Temnospondyli: Dissorophoidea), the interrelationships of amphibamids, and the origin of modern amphibians. Journal of Vertebrate Paleontology, 30(5):1360-1377. https://doi.org/ 10.1080/02724634.2010.501445

Sigurdsen, T. and Green, D.M. 2011. The origin of modern amphibians: a re-evaluation. Zoological Journal of the Linnean Society, 162(2):457-469. https://doi.org/10.1111/j.10963642.2010.00683.x

Sullivan, C., Reisz, R.R., and May, W.J. 2000. Large dissorophoid skeletal elements from the Lower Permian Richards Spur fissures, Oklahoma, and their paleoecological implications. Journal of Vertebrate Paleontology, 20(3):456-461. https://doi.org/10.1671/02724634(2000)020[0456:LDSEFT]2.0.CO;2

Williston, S.W. 1910a. Cacops, Desmospondylus; new genera of Permian vertebrates. Geological Society of America Bulletin, 21(1):249-284. https://doi.org/10.1130/GSAB-21-249 
Williston, S.W. 1910b. Dissorophus Cope. Journal of Geology, 18(6):526-536.

Witzmann, F. 2005. A dissorophid temnospondyl in the Upper Permian Kupferschiefer of Germany. Neues Jahrbuch für Geologie und Paläontologie Monatshefte 2005:289-300.

Witzmann, F. and Soler-Gijón, R. 2010. The bone histology of osteoderms in temnospondyl amphibians and in the chroniosuchian Bystrowiella. Acta Zoologica, 91(1):96-114. https:// doi.org/10.1111/j.1463-6395.2008.00385.x

von Zittel, K.A. 1888. Handbuch der Paläeontologie. Abteilung 1. Paläozoologie Band III. Vertebrata (Pisces, Amphibia, Reptilia, Aves). Oldenbourg, Munich, Germany. 


\section{APPENDIX 1.}

Comparative measurement table for Cacops morrisi. Measurement abbreviations: $\mathbf{M L}$, maximum length of skull across preserved regions; MW, maximum width across posterior skull table; NI, narrowest interorbital width; Pin, anterior pineal foramen margin to anterior margin of the nuchal ridge; PosO, postorbital length from posterior orbital margin to anterior margin of the nuchal ridge; PreO, preorbital length from premaxilla to anterior orbital margin; $\mathbf{R} \mathbf{L}$, skull roof length from anterior tip of premaxilla to nuchal ridge. The width measurements for OMNH 53077, OMNH 73206a, and OMNH 73206c were calculated by mirroring across the midline along the posterior skull region. tan underestimate due to limited incomplete exposure or damage. A reference image for how measurements were made is given in Appendix 2.

\begin{tabular}{ccccccc}
\hline DIMENSION & $\begin{array}{c}\text { OMNH } \\
\mathbf{5 3 0 7 3}\end{array}$ & $\begin{array}{c}\text { OMNH } \\
\mathbf{5 3 0 7 7}\end{array}$ & $\begin{array}{c}\text { OMNH } \\
\mathbf{7 3 2 0 6 a}\end{array}$ & $\begin{array}{c}\text { OMNH } \\
\mathbf{7 3 2 0 6 b}\end{array}$ & $\begin{array}{c}\text { OMNH } \\
\mathbf{7 3 2 0 6} \mathbf{c}\end{array}$ & $\begin{array}{c}\text { OMNH } \\
\mathbf{7 9 3 3 9}\end{array}$ \\
\hline $\mathrm{ML}$ & 9.2 & 13.4 & 10.3 & - & 11.5 & $\dagger 10.2$ \\
$\mathrm{MW}$ & 6.4 & 10.1 & 8.0 & +6.5 & 8.5 & 7.9 \\
$\mathrm{NI}$ & 1.4 & 2.2 & 1.8 & 1.4 & - & 1.7 \\
$\mathrm{Pin}$ & 1.7 & 2.2 & 1.9 & - & - & - \\
PosO & 1.7 & 2.7 & 1.9 & - & - & 1.9 \\
PreO & 2.9 & 4.8 & 3.4 & 3.0 & 4.2 & 3.7 \\
$\mathrm{RL}$ & 7.4 & 10.8 & 8.2 & - & - & 8.5 \\
\hline
\end{tabular}




\section{APPENDIX 2.}

Reference figure of OMNH 79338 (Cacops woehri) showing how cranial measurements were taken for Appendices 1 and 3 (refer to appendices for abbreviations). Note that the narrowest interorbital width (NI) and the maximum width (MW) were doubled for this specimen as it represents only half of the skull.

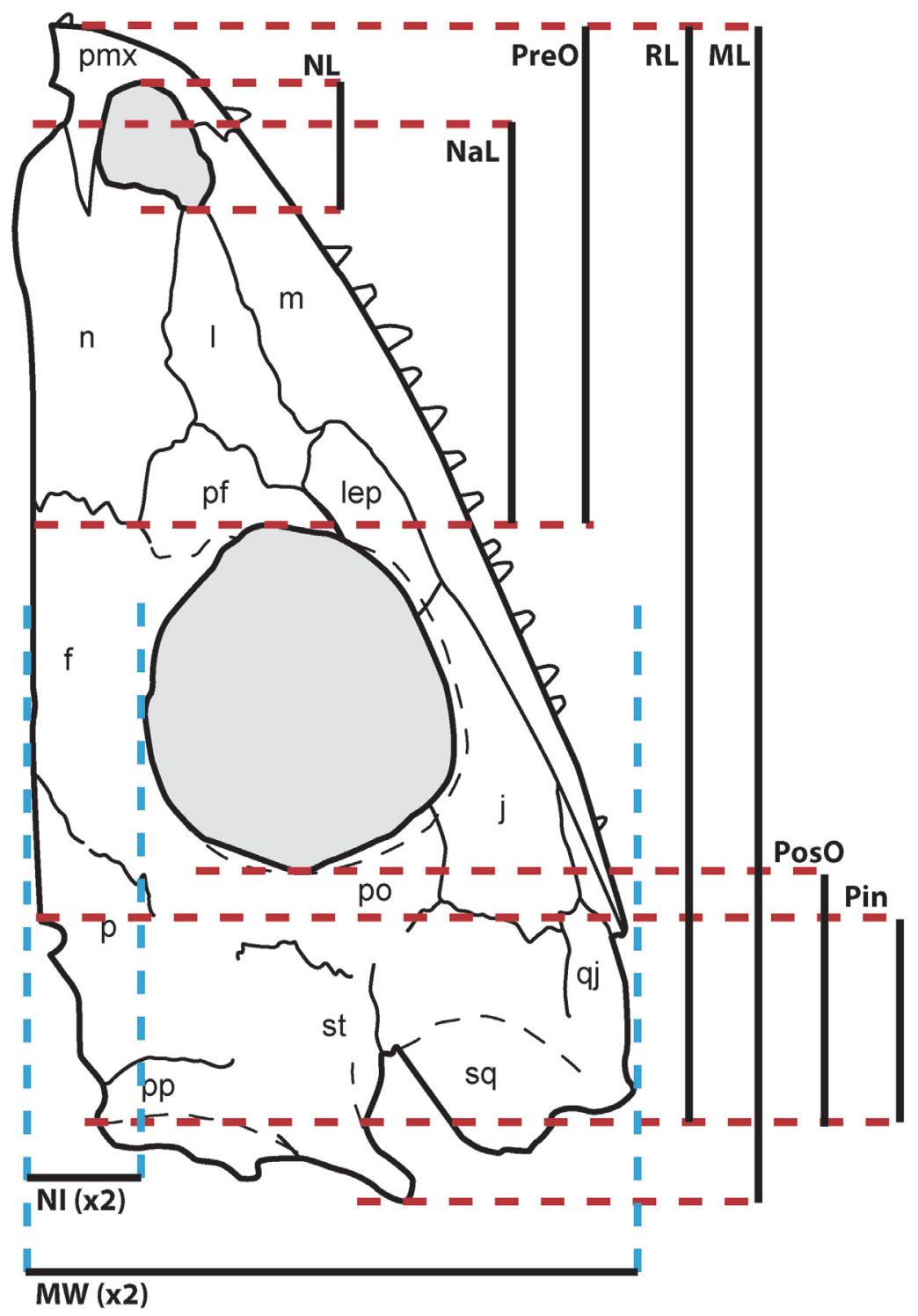




\section{APPENDIX 3.}

Comparative measurement table for Cacops woehri. Measurement abbreviations: Measurement abbreviations: $\mathbf{M L}$, maximum length of skull across preserved regions; $\mathbf{M W}$, maximum width across posterior skull table; NaL, maximum length of nasal; NI, narrowest interorbital width; NL, maximum length of external naris; Pin, anterior pineal foramen margin to nuchal ridge; PosO, postorbital length from posterior orbital margin to nuchal ridge; PreO, preorbital length from premaxilla to anterior orbital margin; RL, skull roof length from anterior tip of premaxilla to nuchal ridge. The width measurements for $\mathrm{OMNH} 73216$ and $\mathrm{OMNH} Y$ was calculated by mirroring across the midline. ta slight underestimate due to limited incomplete exposure or damage. §a slight overestimate due to limited incomplete exposure or damage. A reference image for how measurements were made is given in Appendix 2.

\begin{tabular}{cccccc}
\hline DIMENSION & $\begin{array}{c}\text { OMNH } \\
\mathbf{7 3 2 1 6}\end{array}$ & $\begin{array}{c}\text { BMRP } \\
\mathbf{2 0 0 7 . 3 . 5}\end{array}$ & $\begin{array}{c}\text { OMNH } \\
\mathbf{7 9 3 3 8}\end{array}$ & $\begin{array}{c}\text { ROMVP } \\
\mathbf{8 0 0 8 0}\end{array}$ & $\begin{array}{c}\text { ROMVP } \\
\mathbf{8 0 0 8 1}\end{array}$ \\
\hline $\mathrm{ML}$ & $\dagger 7.0$ & - & +9.1 & - & - \\
$\mathrm{MW}$ & 5.0 & 6.9 & $\S 9.1$ & - & - \\
$\mathrm{NaL}$ & 2.1 & - & 2.7 & $\S 2.6$ & 2.3 \\
$\mathrm{NI}$ & 1.1 & 1.5 & 1.6 & - & - \\
$\mathrm{NL}$ & 0.7 & - & 0.9 & +0.7 & 0.8 \\
$\mathrm{Pin}$ & 1.3 & 1.6 & 1.5 & - & - \\
$\mathrm{PosO}$ & 1.3 & 1.6 & 1.9 & - & - \\
PreO & 2.5 & - & 3.8 & - & - \\
$\mathrm{RL}$ & 6.2 & - & 8.4 & - & - \\
\hline
\end{tabular}




\section{APPENDIX 4.}

Isolated right humerus of an indeterminate dissorophid, FMNH UC 1086. 1, Photograph in flexor profile; 2, photograph in anterior profile; $\mathbf{3}$, photograph in extensor profile; 4, photograph in posterior profile. Scale bar equals $1 \mathrm{~cm}$.
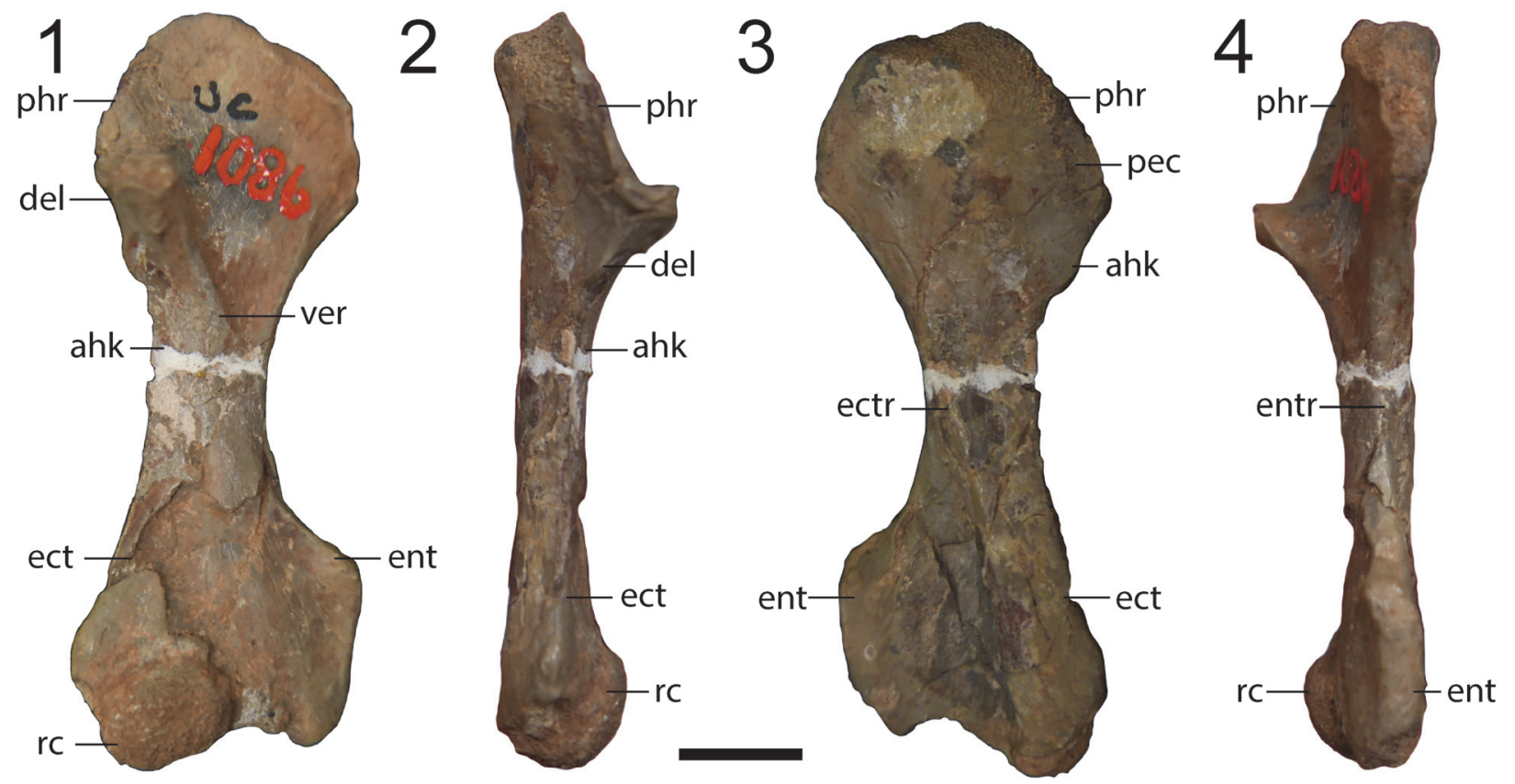